ONDERZOEKSRAPPORT NR 9324

The Exchange Rate in the Presence of Transaction Costs : Implications for Tests of Purchasing Power Parity

by

Piet SERCU

Raman UPPAL

Cynthia VAN HULLE

$\mathrm{D} / 1993 / 2376 / 24$ 


\title{
The Exchange Rate in the Presence of Transactions Costs: Implications for Tests of Purchasing Power Parity
}

\author{
by
}

Piet Sercu
DTEW, K.U.Leuven
Dekenstraat 2
3000 Leuven
Belgium
Tel: $(+32)(0) 16-285772$
Fax: $(+32)(0) 16-285799$

\author{
Raman Uppal \\ Finance Division \\ Univ. of British Columbia \\ Vancouver B.C. V6T $1 Z 2$ \\ Canada \\ Tel: (604)822-8331 \\ Fax: (604)822-8521
}

\author{
Cynthia Van Hulle \\ DTEW, K.U.Leuven \\ Dekenstraat 2 \\ 3000 Leuven \\ Belgium \\ Tel: $(+32)(0) 16-285737$ \\ Fax: $(+32)(0) 16-285799$
}

August 1993 


\title{
The Exchange Rate in the Presence of Transactions Costs: Implications for Tests of Purchasing Power Parity
}

\author{
Abstract \\ With transactions costs for trading goods, the nominal exchange rate moves within a \\ band around the nominal PPP value. We model the behavior of the band and of the \\ exchange rate within the band using a contingent claim valuation approach. This model \\ predicts that there will be below-unity coefficients in regression tests of PPP even if \\ there were no errors in variables; it also offers an explanation why the relation between \\ exchange rate changes and inflation differentials improves under hyperinflation or in \\ the long run. JEL F31
}




\section{The Exchange Rate in the Presence of Transactions Costs: Implications for Tests of Purchasing Power Parity}

The objective of this article is to develop a model of the exchange rate that explains the following two stylized empirical facts about deviations from relative Purchasing Power Parity (PPP). First, in a simple regression of changes in the (nominal) exchange rate on inflation differentials, the coefficient is typically below unity. Second, the coefficient increases with the length of the observation interval, and the PPP link is also stronger under hyper-inflation. ${ }^{1}$ The low coefficients in the relative PPP regression, especially when tested over short periods of time, are often ascribed to errors-in-variables biases. ${ }^{2}$ However, many of these empirical tests do not specify the nature of these errors. It is true that there are measurement problems introduced by, for example, infrequent price sampling for some items, and the non-synchroneity among the prices composing the index. Also, noise is introduced by price indices which are weighted differently across countries and by the presence of non-tradeable goods. ${ }^{3}$ But if these were the only problems, PPP would be reduced to the truism that we should observe price parity if we had perfect data on individual, perfectly tradeable goods.

We adopt an alternative (or, preferably, complementary) approach to explain the observed deviations from PPP. We focus on the effect of costs for trading goods (such as shipping and insurance costs, tariffs, information costs and other barriers to trade) on the exchange rate. In our model, there are two factors which influence the exchange rate: the

\footnotetext{
${ }^{1}$ See, for example, McNown and Wallace (1989). Also, improved econometric methods have contributed to stronger tests of PPP. These include more powerful tests of serial independence in relative PPP deviations (Abuaf and Jorion (1990) and Huizinga (1987)), joint estimation (Apte, Kane, and Sercu (1992), Hakkio (1984), Koedijk and Schotman (1990), Phylaktis and Kassimatis (1992)), and cointegration tests (Baillie and Selover (1987), Corbae and Ouliaris (1988), Enders (1988), Kim (1990), Phylaktis and Kassimatis (1992) and Taylor (1988)).

${ }^{2}$ See, for example, Apte, Kane, and Sercu (1992), Betton, Levi, and Uppal (1992), Cumby and Obstfeld (1984), Hakkio (1984), Hansen and Hodrick (1980, 1983), Huang (1990) and Rush and Husted (1985).

${ }^{3}$ For evidence of this see, Kravis, Kennessey, Heston and Summers (1975).
} 
relative outputs of the tradeable good at home and abroad, and the relative money supplies. As is well known, when trading is costly, the nominal exchange rate can deviate from the nominal price-parity value, but by no more than the transactions cost. The reason is that trade takes place if and only if the price difference between the domestic and foreign tradeable good is large enough to compensate for this transactions cost. Thus, friction introduces (bounded) 'noise' in the price-parity relationship. In order to understand the effect of this noise on the regression coefficient in a relative PPP test, we need a theory about the movements of the band, and the behavior of the exchange rate within the band.

To obtain such a theory, we view international trade, the prices of tradeable goods, and the exchange rate as processes contingent on the stochastic outputs of the tradeable goods. Accordingly, we determine the exchange rate using a contingent claim valuation approach with the outputs of tradeable goods in each economy treated as the state variables. We show that, within the transactions-cost band, the elasticity of the spot rate relative to the ratio of the two prices of tradeable goods is below unity. Thus, in our view the below-unity coefficients found in tests of relative PPP over short periods of time partly reflect a true phenomenon rather than just an errors-in-variables bias. One-to-one links between relative price changes and exchange rate movements are observed only if the exchange rate remains at one edge of the no-trade region, or if the exchange rate and the boundary are all changing by the same factor. We argue that hyperinflation episodes are close to such situations. Thus, our model offers at least a partial explanation for the stylized facts in the empirical literature on PPP.

As in Dumas (1992), we introduce a proportional cost for transferring goods between countries. ${ }^{4}$ However, there are several differences between our model and that of Dumas. First, while the model of Dumas is of a single good economy, we model an economy with two goods-a non-traded good and a tradeable good. This is a closer approximation to real

\footnotetext{
${ }^{4}$ For a non-stochastic version of this model, see Black (1973).
} 
world economies that have many goods, most of them non-traded. For instance, consumption patterns in OECD countries are heavily composed of services, with weights of 60 to $80 \%$; and many of the remaining manufactured goods are not easily traded. Thus, models with a single good are likely to overstate the linkages between trade, overall consumption, wealth, and exchange rates.

A second difference with Dumas' model is that he considers a production economy where the single (tradeable) good serves simultaneously as the capital good and the consumption good. Our model, in contrast, is of an endowment economy where the tradeable good is a pure consumption good. As far as one can judge from tests of PPP, the consensus view is that it is trade in consumption goods, rather than trade in capital goods, that drives exchange rates. While our endowment processes of the tradeable good are risky, we assume that the endowment processes for the non-traded goods at home and abroad are riskless. This assumption is motivated by the empirical observation that the aggregate output of services, representing the bulk of non-tradeable goods, tends to be far less cyclical than industrial production, and more importantly, that there seems to be no strong link between the activity in the non-tradeable good sector and exchange rate changes. This assumption implies the existence, in each country, of an asset with a return that is riskless in terms of the local nontraded good. Thus, a third difference with Dumas' model is that these riskless rates of return in our model are determined exogenously ${ }^{5}$ while in the model of Dumas the real interest rate in each country is determined endogenously. The major analytical advantage of our assumption is that, in contrast to the model of Dumas, it allows us to obtain closed-form solutions for the exchange rate and other variables of interest. Finally, we focus on the nominal exchange rate while the model of Dumas studies the real exchange rate.

The rest of the article is organized as follows. We describe the model in Section 1. In Section 2, we derive the bounds that the exchange rates must satisfy in the presence of

\footnotetext{
${ }^{5}$ Nominal interest rates and real interest rates (defined in terms of the representative consumption bundle rather than in terms of one good) can still be solved for endogenously.
} 
transactions costs. In Section 3, using the contingent claim valuation approach, we determine the exchange rate. The implications of our model for tests of PPP are presented in Section 4. We present our conclusions in Section 5. All mathematical symbols used are summarized in the Index to Notation following Appendix B.

\section{The Model}

In this section, we present a model of two countries that have perfectly integrated financial markets but segmented markets for real goods. That is, capital markets are assumed to be complete and frictionless (implying that asset prices are equal across countries, after conversion into the same reference currency), but it is costly to trade goods internationally. Below, we describe the preferences, the production technologies and the conditions for trade. Throughout the paper, variables related to the domestic economy (arbitrarily chosen) are shown in lower-case and those related to the foreign country are shown in upper-case symbols.

The two countries are populated by a large number of infinitely lived consumers with identical preferences, and the production technologies in both countries are of the same form. Each country is characterized by endowment processes for two goods: ${ }^{6}$ a non-traded good, and a tradeable consumption good that is non-storable and homogenous across countries. Variables related to the non-tradeable sectors will be denoted by a prime ('). Much of the analysis in the main text discusses the symmetric case. In a decentralized setting, this corresponds to an equal number of consumers in each country, an equal initial output for the traded good, and likewise for the non-traded good.

The assumption that there are two goods in each country creates a role for money as

${ }^{6}$ The fact that we have endowment processes implies that there is no labor income. The agents' wealths and incomes consist of shares and dividends only. 
the least-cost medium of exchange. We assume that money is created, as in Fama and Farber (1979), by the country's government, which uses the seignorage to sustain the economic environment. As the government's needs may change stochastically over time, the money supply may also change stochastically over time. The domestic and foreign goods prices referred to in this paper are expressed in units of the corresponding country's currency. These prices may change over time because the local money supply changes, or because quantities available for consumption change.

We assume that the outputs in the non-tradeable good sector at home $\left(q^{\prime}(t)\right)$ and abroad $\left(Q^{\prime}(t)\right)$ are riskfree:?

$$
\begin{aligned}
\frac{\mathrm{d} q^{\prime}(t)}{q^{\prime}(\mathrm{t})} & =\phi \mathrm{d} t \\
\frac{\mathrm{d} Q^{\prime}(t)}{Q^{\prime}(\mathrm{t})} & =\Phi \mathrm{d} t
\end{aligned}
$$

and, in the symmetric case,

$$
\phi=\Phi, q^{\prime}(t)=Q^{\prime}(t)
$$

The endowment of the tradeable good at home $(q(t))$ and abroad $(Q(t))$, however, is stochastic and is given by the following processes: ${ }^{8}$

$$
\frac{\mathrm{d} q(t)}{q(t)}=\mu \mathrm{d} t+\sigma \mathrm{d} \omega(t)
$$

$$
\frac{\mathrm{d} Q(t)}{Q(t)}=\mu \mathrm{d} t+\sigma \mathrm{d} \Omega(t)
$$

Note that, for expositional ease, we assume that $\mu$ and $\sigma$ are the same across countries, but

\footnotetext{
${ }^{7}$ See the introduction for the motivation underlying the assumption that the production processes for the nontraded goods are riskless.

${ }^{8}$ The lognormal process gives convenient properties for the derivative processes. For instance, in the absence of trade, the tradeable goods prices $p(t)$ and $P(t)$ will be lognormal, and also the nominal exchange rate $S(t)$ will be lognormal-consistent with, for example, the models Adler and Dumas (1983), Breeden (1979), Fisher (1973), Sercu(1980), Solnik(1973) and Stulz (1981). Moreover, the solution in this case allows for straightforward comparisons with the classical model where $S(t)=p(t) / P(t)$.
} 
this assumption can be relaxed without qualitatively changing any of the conclusions. The correlation between the Wiener processes $d \omega(t)$ and $d \Omega(t)$ is denoted by $k$, which is less than unity.

Two factors distinguish one country from another. First, the shocks in the outputs of the tradeable good in each country contain a country-specific element; and second, it is costly to transfer the traded good from one country to another. Thus, within a certain region, even when the price of the tradeable good at home is different from that abroad it will be optimal not to trade. This cost is modelled, following Dumas (1992), as a waste of resources: if one unit is shipped, only $1 /(1+\tau)$ units actually arrive. From the individual trader's point of view, $\tau$ has the dimensions of an ad valorem duty: in order to obtain one net unit at home, the trader has to spend $(1+\tau) P(t)$ units of foreign currency (with $P(t)$ denoting the foreign-currency price of the tradeable good). ${ }^{9}$ Before considering individual traders and decentralized decision-making, we shall first look at the problem from a central planner's perspective. Analyzing the central planner's problem allows us to identify the no-trade region as well as the sharing rule for consumption, in a relatively straightforward way. With complete financial markets, the decentralized solution will be identical to that of the central planner. ${ }^{10}$

Let $c(t)$ be the domestic representative agent's rate of consumption of the traded good (measured as a number of units), and $c^{\prime}(t)$ the consumption rate of the non-traded good in the home country. $C(t)$ and $C^{\prime}(t)$ denote the foreign counterparts. Finally, let $x(t)$ denote the home country's rate of exporting, and let $X(t)$ denote the foreign country's exports (both before transactions costs). The central planner's objective is to chose the traded amounts so that the weighted aggregate utility is maximised:

\footnotetext{
9Note, however, that this 'ad valorem cost' is dissipative: it does not accrue to any agent in the economy. Thus, $1 /(1+\tau)$ corresponds to the symbol $s$ in Dumas (1992) or Uppal (1993), the fraction of goods that survives shipping.

10Dumas (1992) analyzes the central planner's problem. Uppal (1993) shows that the same solution is obtained in a decentralized setting.
} 


$$
\begin{aligned}
& \operatorname{Max} \lambda^{*} E \int_{0}^{\infty} e^{-\rho t} u\left[c_{i}(t), c_{i}^{\prime}(t)\right] d t,+\left(1-\lambda^{*}\right) E \int_{0}^{\infty} e^{-\rho t} U\left[C_{i}(t), C_{i}^{\prime}(t)\right] d t, \\
& \text { subject to } \begin{aligned}
c(t) & =q(t)-x(t)+\frac{X(t)}{1+\tau} \\
C(t) & =Q(t)-X(t)+\frac{x(t)}{1+\tau} \\
x(t) & \geq 0, X(t) \geq 0 \\
c^{\prime}(t) & =q^{\prime}(t), C^{\prime}(t)=Q^{\prime}(t)
\end{aligned}
\end{aligned}
$$

Note that in the first and second constraints, a shipment of $x(t)$ from the home country leads to an increase in foreign consumption of only $x(t) /(1+\tau)$, and likewise for shipments in the other direction. The last two constraints state that, for the nontradeable good, consumption equals local output. In the symmetric case, we have $q^{\prime}(t)=Q^{\prime}(t)$ and $\lambda^{*}=1-\lambda^{*} .11$ For mathematical tractability, we assume that commodity preferences are represented by $u\left[c_{i}(t), c_{i}^{\prime}(t)\right]=\frac{\left[c(t)^{\varepsilon} c^{\prime}(t) 1^{1-\varepsilon}\right]^{1-\eta}}{1-\eta}$, where $\eta(>0)$ is relative risk aversion.

In the absence of shipping costs, the central planner would select an optimal relative rate of consumption $C(t) / c(t)$ and correct any deviation of $Q(t) / q(t)$ from the optimal solution by shipping goods. If, moreover, the countries are equal, i.e. $q^{\prime}(t)=Q^{\prime}(t)$ and $\lambda^{*}=\left(1-\lambda^{*}\right)$, the optimal consumption ratio would equal unity. But in the presence of shipping costs, there will be a no-trade zone within which deviations of $C(t) / c(t)$ from the 'optimum' will be left uncorrected. As we shall show, the magnitude of the no-trade region depends on the level of transactions cost $\tau$, the openness of the economy $(\varepsilon)$, and the degree of relative risk aversion $(\eta)$. The central planner's decision rules are summarized in the following proposition:

Proposition 1: Given a proportional transactions cost and iso-elastic utility, the no-trade

\footnotetext{
${ }^{11}$ The case $\lambda^{*}=1-\lambda^{*}$ corresponds to the decentralized situation with equal initial endowments in the two countries. The initial endowments determine the initial relative wealth of the two countries; this, in complete markets, then determines how the claims on future consumption are distributed among the countries.
} 
region is bounded by two rays through the origin: 12

$$
\begin{aligned}
X(t)=0=x(t) & \Leftrightarrow \kappa_{2}(t) \leq \frac{Q(t)}{q(t)} \leq \kappa_{1}(t), \\
X(t)>0 & \Leftrightarrow \frac{Q(t)}{q(t)}>\kappa_{1}(t), \\
x(t)>0 & \Leftrightarrow \frac{Q(t)}{q(t)}<\kappa_{2}(t),
\end{aligned}
$$

where $\kappa_{1}(t)>\kappa_{2}(t)$. If $Q(t) / q(t)$ is outside the no-trade region, the shipped amounts will be such that $C(t) / c(t)$ remains on the nearest bound $\kappa_{1}(t)$ or $\kappa_{2}(t)$. When the two countries are equal-that is, when the weights $\lambda^{*}$ and $1-\lambda^{*}$ assigned to each country are equal, and the nontradeable good outputs $q^{\prime}(t)$ and $Q^{\prime}(t)$ are also identical-we obtain a time-invariant cone which is symmetric around the 45-degree line: $\kappa_{1}(t)=\kappa \equiv(1+\tau)^{1 /(1-\varepsilon(1-\eta))}=1 / \kappa_{2}(t) .{ }^{13}$

\section{Proof: See Appendix A.}

Figure 1 illustrates the case of identical countries, implying a symmetric cone $\kappa_{1}(t)=\kappa=$ $1 / \kappa_{2}(t)$. Thus, for $Q(t) / q(t)>\kappa$ there will be exports from the foreign country; for $Q(t) / q(t)<$ $1 / \kappa$ there will be exports from the home country; and there is no trade when $Q(t) / q(t)$ is strictly within the cone of no shipping, or at one of its boundaries.

Having identified the region of no shipping and the sharing rule when trade is positive, we now price the nominal exchange rate. In Section 2 we identify the bounds on the exchange rate, as well as the pricing formula for the exchange rate when $Q(t) / q(t)$ is outside the cone of no shipping. In Section 3, we derive the exchange rate when $Q(t) / q(t)$ is within the cone.

12Dumas [1992] and Davis and Norman [1990] have obtained this result in somewhat different settings.

13 If the number of consumers differs, or if the initial endowments differ across countries (i.e. when $\lambda^{*} \neq 1-\lambda^{*}$ ), the no-shipping region will not be symmetric around the 45-degree line. If, in addition, the relative output $Q^{\prime}(t) / q^{\prime}(t)$ is not constant, the cone of no shipping will change deterministically over time. See Appendix A. 


\section{The Value of the Exchange Rate at the Boundaries}

In this section, we examine the effect on the nominal exchange rate of the transactions cost incurred for transferring the tradeable good between countries. To preclude arbitrage opportunities the exchange rate must satisfy certain bounds. We first express the bounds relative to the prices of the traded-goods prices, and then link the prices to the primitive in the model, the outputs. ${ }^{14}$ We then derive the exchange rate for $(Q(t), q(t))$ on the bounds and outside the cone of no shipping.

Let $S(t)$ denote the nominal spot exchange rate, in units of domestic currency per unit of foreign currency. In order to import one (net) unit of the tradeable good from abroad into the home country, the importer has to buy $(1+\tau)$ units of this good at the foreign price $P(t)$. In the absence of arbitrage opportunities, the all-in cost of the foreign good must be no lower than the domestic price $p(t)$ :

$$
S(t) P(t)(1+\tau) \geq p(t)
$$

Combining (5) with a symmetric relation for exports, gives us the two bounds that the nomiual exchange rate $S(t)$ must satisfy in the absence of arbitrage opportunities:

$$
\frac{p(t)}{P(t)(1+\tau)} \leq S(t) \leq \frac{p(t)(1+\tau)}{P(t)}
$$

It should be clear that an exchange rate strictly within the band is a sufficient condition for zero trade, because under these circumstances a trader would incur losses from either exporting or importing. To obtain positive imports [exports], it is necessary that the lower [upper] bound hold as an equality: this ensures that there are no losses-although

\footnotetext{
${ }^{14}$ Benninga and Protopapadakis (1988) derive one-sided 'forward' bounds when trading takes time. They also express the exchange rate in terms of general state prices, but without closed-form solution. We have two-sided bounds, and a closed-form solution.
} 
international trade, like any other arbitrage transaction in competitive markets, remains a zero-profit operation. Also note that in the event of an equality in (6) there need not be any trade; specifically, when $Q(t), q(t)$ is exactly on one of the boundaries of the cone of no shipping, there is still no trade; but, by virtue of the value matching conditions, provided in Appendix B, the exchange rate must satisfy the corresponding bound in (6).

The bounds in (6) suggest that the exchange rate is contingent on the prices of the two tradeable goods. However, these prices, $p(t)$ and $P(t)$, cannot be taken to be exogenous processes. The next step, accordingly, is to relate the price of each country's tradeable good, and therefore the exchange rate bounds, to the local money supply and to the aggregate consumption of each tradeable good (which from Proposition 1 is a known function of the exogenous output processes). We start from the individual investor's problem.

Define $W_{i}(t)$ as investors $i$ 's wealth, $w_{i j}(t)$ as the value weight of asset $j$ in $i$ 's portfolio, $\frac{\mathrm{d} V_{j}(t)}{V_{f}(t)}$ as the return on asset $j$, and $b_{i}(t)$ as the individual's rate of nominal consumption expenditures. Then the $i$-th investor's intertemporal problem is to choose the optimal portfolio weights and consumption rates to solve:

$$
\begin{gathered}
\operatorname{Max} \mathrm{E}\left(\int_{0}^{\infty} \mathrm{e}-\mathrm{ps} \frac{\left[c_{i}(t)^{\varepsilon} c_{i}^{\prime}(t)^{1-\varepsilon}\right]^{1-\eta}}{1-\eta} \mathrm{d} s\right) \\
\mathrm{d} W_{i}(t)=W_{i}(t)\left[\sum_{j} w_{i j}(t) \frac{\mathrm{d} V_{j}(t)}{V_{j}(t)}\right]-b_{i}(t) \mathrm{dt}, \\
c_{i}(t) p(t)+c_{i}^{\prime}(t) p^{\prime}(t)=b_{i}(t)
\end{gathered}
$$

The following Lemma restates the above problem to allow us to link prices to outputs and money supplies:

Lemma 1: The agent's problem given above can be written as

$$
\operatorname{Max} E\left(\int_{0}^{\infty} \mathrm{e}^{-\rho \mathrm{s}} \frac{\chi_{i}(t)^{1-\eta}}{1-\eta} \mathrm{d} s\right)
$$

s.t.

$$
\mathrm{d} W_{i}(t)=W_{i}(t)\left[\Sigma_{j} w_{i j}(t) \frac{\mathrm{d} V_{j}(t)}{V_{j}(t)}\right]-b_{i}(t) \mathrm{dt},
$$




$$
\chi_{i}(t) \pi(t)=b_{i}(t)
$$

as if there were just one composite good, consumed at a rate $\chi_{\mathrm{i}}(t)$, and one price $\pi(t)$. The link between the two optimization problems is

$$
\chi_{i}(t)=\operatorname{Max} c_{i}(t)^{\varepsilon} c_{i}^{\prime}(t)^{1-\varepsilon} \text { s.t. } c_{i}(t) p(t)+c_{i}^{\prime}(t) p^{\prime}(t)=b_{i}(t)
$$

The demand equations and the general price index induced by the latter problem are

$$
\begin{gathered}
c_{i}(t)=\frac{\varepsilon b_{i}(t)}{p(t)} \quad \text { and } \quad c_{i}^{\prime}(t)=\frac{(1-\varepsilon) b_{i}(t)}{p^{\prime}(t)} \\
\pi(t)=\varepsilon^{-\varepsilon}(1-\varepsilon)^{\varepsilon-1} p(t)^{\varepsilon} p^{\prime}(t)^{1-\varepsilon}
\end{gathered}
$$

Proof: See Samuelson and Swamy (1974), or Grauer, Litzenberger, and Stehle (1976).

The existence of a composite commodity and a price index will be useful in Section 3 when we invoke the consumption CAPM to determine the risk premium. For immediate purposes, we just need the demand equations (7). From these, we infer that aggregate consumption of the tradeable good, over all consumers at home, equals $\frac{\varepsilon \sum_{i} b_{i}(t)}{p(t)}$. By definition, this aggregate demand or aggregate consumption $c(t)$ must equal domestic output of the tradeable good, $q(t)$, plus imports net of the cost, $X(t) /(1+\tau)$, less (gross) exports $x(t)$; that is, $c(t)=\frac{\varepsilon \Sigma_{i} b_{i}(t)}{p(t)}=q(t)+X(t) /(1+\tau)-x(t)$. A similar argument can be used to relate the non-traded good price to the (risk-free) aggregate output $q^{\prime}(t)$. Finally, aggregate expenditures $\Sigma_{i} b_{i}(t)$ must, by definition, equal the money supply $m(t)$ times the velocity $v$ of money. 15 Therefore, we can rewrite equations (7) as:

$$
\begin{aligned}
& p(t)=\frac{\varepsilon \sum_{i} b_{i}(t)}{c(t)}=\frac{\varepsilon v m(t)}{c(t)} \text { where } c(t)=q(t)+\frac{X(t)}{1+\tau}-x(t) \\
& p^{\prime}(t)=\frac{(1-\varepsilon) v m(t)}{q^{\prime}(t)}
\end{aligned}
$$

\footnotetext{
${ }^{15}$ For simplicity of notation, we assume a constant and identical velocity of money in each country. If velocities are not contant, it suffices to replace $m(t)$ by $v(t) m(t)$ throughout the paper, and likewise for the other country.
} 
The foreign-country counterparts are analogous.

Since the output $q^{\prime}(t)$ of the non-traded good is non-stochastic, the only source of uncertainty about its price $p^{\prime}(t)$ is the money supply, $m(t)$. In contrast, the traded good's price, $p(t)$, depends also on the domestic output $q(t)$ and, via $X(t)$ and $x(t)$, on the foreign output $Q(t)$.

Substitution of (9) into (6) allows us to specialize the bounds on the exchange rate as follows:

$$
\frac{1}{1+\tau} \frac{m(t)}{M(t)} \frac{C(t)}{c(t)} \leq S(t) \leq(1+\tau) \frac{m(t)}{M(t)} \frac{C(t)}{c(t)}
$$

where $C(t)=Q(t)-X(t)+\frac{x(t)}{1+\tau}, c(t)=q(t)+\frac{X(t)}{1+\tau}-x(t)$, and $X(t) \geq 0, x(t) \geq 0$. Now consider the case where the two countries are identical. When $Q(t) / q(t)$ is above or on the upper ray, then from Proposition 1 we have $C(t) / c(t)=\kappa$. Likewise, we have $C(t) / c(t)=1 / \mathrm{\kappa}$ when $Q(t) / q(t)$ is below or on the lower ray. Equation (10) then implies the following:

Proposition 2: On and outside the boundaries of the no-shipping zone, the exchange rate is given by

$$
\begin{array}{ll}
\text { for } Q(t) \geq \kappa q(t): & S(t)=\frac{p(t)}{P(t)(1+\tau)}=\frac{m(t)}{M(t)} \frac{\kappa}{1+\tau}, \\
\text { for } Q(t) \leq \frac{q(t)}{\kappa}: & S(t)=\frac{p(t)(1+\tau)}{P(t)}=\frac{m(t)}{M(t)} \frac{1+\tau}{\kappa} .
\end{array}
$$

Note that, when $\tau=0$ (that is, $\kappa=1$ ), then $S(t)=\frac{m(t)}{M(t)}$. That is, in the absence of shipping costs, relative money supply is the sole determinant of the exchange rate. If financial markets are complete and perfect, there exists a decentralized portfolio strategy that implements the optimal consumption and shipping policies. In the zero-cost case with identical initial endowments for the two countries, the decentralized strategy is that both countries hold the same portfolio and consume the same amounts. When costs are positive, the equilibrium will not be a pooled one and the two countries' portfolio holdings will be different; but there still 
exists a decentralized portfolio strategy that implements the central planner's solution.

In the next section, we determine the exchange rate when $(Q(t), q(t))$ is within the notrade region.

\section{Determination of the Exchange Rate in the No-Trade Region}

In this section, we determine the equilibrium exchange rate within the cone of no shipping. This rate is identified in two steps. In the first step, we temporarily change numeraires, and express prices in units of the non-traded good. That is, we divide all goods and asset prices by $p^{\prime}(t)$ (at home) or $P^{\prime}(t)$ (abroad), and solve for the (transformed) exchange rate $Z(t)=$ $S(t) \frac{P^{\prime}(t)}{p^{\prime}(t)} \cdot{ }^{16}$ In the second step, we translate this solution back to standard monetary units. The change of numeraire is analytically convenient for two purposes. First, the non-traded goods sector being risk-free, in each country" there is an asset with a technology-determined return, $\phi$, that is riskfree in units of the non-traded good. Second, by expressing prices in terms of the non-traded good, we eliminate the money supplies as state variables. To see this, note that, holding constant the real variables, the exchange rate is proportional to the relative money supply (see e.g. the bounds $(10)$ ). But $p^{\prime}(t) / P^{\prime}(t)$ is also proportional to the relative money supply (see equations $(9 \mathrm{a}, \mathrm{b})$ ). It follows that the transformed exchange rate $Z(t)=S(t) \frac{P^{\prime}(t)}{p^{\prime}(t)}$ is purged of money supply effects. Thus, the temporary change of numeraire allows a substantial simplification of the problem. ${ }^{17}$

To price $Z(t)$, we first consider the boundary conditions for $Z(t)=S(t) P^{\prime}(t) / P^{\prime}(t)$. Using (9), we can transform the boundary conditions in (11) and (12) to
(14a) for $Q(t) \geq \kappa q(t)$ :

$$
Z(t)=\frac{\kappa}{1+\tau}
$$

\footnotetext{
${ }^{16}$ To buy one unit of the foreign nontradeable good, a foreign consumer needs $P^{\prime}(t)$ foreign currency units, which corresponds to $S(t) P^{\prime}(t)$ home currency units, or $Z(t)=S(t) P^{\prime}(t) / p^{\prime}(t)$ units of the domestic non-tradeable good. Thus, $Z(t)$ is the transformed exchange rate.

${ }^{17}$ A similar change in numeraire has been used in Merton (1973) and Margrabe (1978).
} 
(14b) for $Q(t) \geq \frac{q(t)}{\mathrm{k}}: \quad Z(t)=\frac{1+\tau}{\mathrm{k}}$

which, by design, are now independent of the money supplies. We now specify further the functional relationship between $Z(t)$ and the quantities of tradeable goods, $q(t)$ and $Q(t)$, by observing the following. In our framework, trade occurs only if there is a sufficient divergence in the outputs of the tradeable goods in the two countries. Or, conversely, the prospects of trade are not changed if $Q(t)$ and $q(t)$ both change by the same factor (i.e. if the point $(Q(t), q(t))$ stays on the same ray through the origin). This is a consequence of the assumed lognormal processes for $Q(t)$ and $q(t)$, constant relative risk aversion utility functions, and proportional transactions costs. Thus, $Z(t)$ is homogenous of degree zero in $Q(t)$ and $q(t)$, or the relevant state variable is $Q(t) / q(t) .{ }^{18}$ In Proposition 3 we specify the differential equation for $Z(t)$. This equation can be viewed as a standard no-arbitrage equation for general contingent claims (see e.g. Hull (1989, pp. 176-179)) with the prices of risk specified on the basis of the consumption CAPM.

Proposition 3: Specifying $Z(t)=Z(Q(t) / q(t))$, and denoting the first and second partial derivatives of $Z(t)$ with respect to the variable $Q(t) / q(t)$ by $Z^{\prime}$ and $Z^{\prime \prime}$, the ordinary differential equation that $Z(t)$ must satisfy in equilibrium is:

$$
0=Z^{\prime}\left[\frac{Q(t)}{q(t)}\right] \alpha(t)+\frac{1}{2} Z^{\prime \prime}\left[\frac{Q(t)}{q(t)}\right]^{2} \delta^{2}
$$

where $\alpha(t)=\sigma^{2}(1-k)-\varepsilon(\eta-1) \frac{\mathrm{d}(Q(t) / q(t))}{Q(t) / q(t)} \frac{\mathrm{d} c(t)}{c(t)} \frac{1}{\mathrm{~d} t}$ and $\delta^{2}=2 \sigma^{2}(1-k)$

Proof: See Appendix B.

The term $\delta^{2}$ is the variance of $Q(t) / q(t)$, while $\alpha(t) \mathrm{d} t$ can be interpreted as the riskadjusted drift of the relative output $Q(t) / q(t)$. We now derive the solution for $Z(t)$ when $(Q(t), q(t))$ is within the cone, i.e. when it is not optimal to trade. When there is no trade, then

${ }^{18}$ Other models that use a similar reduction in the state space include Davis and Norman (1990), Dumas (1992) and Uppal (1993). 
$c(t)$ equals $q(t)$. This implies that, within the cone of no shipping, the risk-adjusted mean $\alpha(t) \mathrm{d} t$ in equation (15) simplifies to

$$
\begin{gathered}
\alpha(t)=\sigma^{2}(1-k)-\varepsilon(\eta-1) \frac{\mathrm{d}(Q(t) / q(t))}{Q(t) / q(t)} \frac{\mathrm{d} q(t)}{q(t)} \frac{1}{\mathrm{~d} t} \\
=\sigma^{2}(1-k)-\varepsilon(\eta-1)\left[\frac{\mathrm{d} Q(t)}{Q(t)}-\frac{\mathrm{d} q(t)}{q(t)}+\ldots\right] \frac{\mathrm{d} q(t)}{q(t)} \frac{1}{\mathrm{~d} t}=\sigma^{2}(1-k)-\varepsilon(\eta-1) \sigma^{2}(k-1) \\
=[1+\varepsilon(\eta-1)] \sigma^{2}(1-k)
\end{gathered}
$$

That is, as long as trade is unprofitable, the risk-adjusted mean is a constant. The next proposition provides the solution to the differential equation when $\alpha(t)$ is a constant.

Proposition 4: Within the no-trade region, the solution of the differential equation (15) subject to the boundary conditions (14) is:

$$
\begin{aligned}
& Z(t)=\left[\frac{Q(t)}{q(t)}\right]^{\beta} \\
& \kappa=(1+\tau)^{1 /(1-\beta)}
\end{aligned}
$$

with $\beta=\varepsilon(1-\eta)<1$. The systems $(16 a, b)$ (within the cone of no shipping) and $(11,12)$ (when there is trade) satisfy the value matching and smooth pasting conditions.

\section{Proof: See Appendix B.}

The relations $\varepsilon<1$ and $\eta>0$ imply that $\beta<1$. Although estimates of relative risk aversion $\eta$ are always somewhat controversial, the consensus is that $\eta$ exceeds unity (the log-utility case), so that $\beta=\varepsilon(1-\eta)$ would be negative. Note also that the result $\kappa=(1+\tau)^{1 /(1-\beta)}$ of this decentralized solution is identical to the central planner's solution.

Equation (16a) gives the solution for the transformed exchange rate $Z(t)$, with the non-traded goods as the numeraires. We can, however, easily revert to the standard exchange rate expressed in monetary units, $S(t)=Z(t) \frac{p^{\prime}(t)}{P^{\prime}(t)}$, by using $(9 \mathrm{~b})$. The result is

$$
S(t)=\frac{m(t)}{M(t)}\left[\frac{Q(t)}{q(t)}\right]^{\beta}, \quad \beta<1
$$


Thus, one determinant of the exchange rate is the relative money supply, $\frac{m(t)}{M(t)}$, and the second component is a real factor, $\left[\frac{Q(t)}{q(t)}\right]^{\beta}$ with $\beta<1$. The effect of $\beta<1$ is to make the real exchange rate drop when foreign output $Q(t)$ rises relative to domestic output $q(t)$. To see this, consider the real exchange rate $S(t) \frac{P(t)}{p(t)}$, and link the prices to the outputs using equation (9):

$$
S(t) \frac{P(t)}{p(t)}=\frac{m(t)}{M(t)}\left[\frac{Q(t)}{q(t)}\right]^{\beta}\left[\frac{M(t) q(t)}{m(t) Q(t)}\right]=\left[\frac{Q(t)}{q(t)}\right]^{\beta-1} \text { when } x(t)=0=X(t)
$$

The derivative of the real exchange rate w.r.t. $Q(t) / q(t)$ is

$$
\frac{\partial\left[S(t) \frac{P(t)}{p(t)}\right]}{\partial[Q(t) / q(t)]}=(\beta-1)\left[\frac{Q(t)}{q(t)}\right]^{\beta-2}
$$

The sign of this derivative is the sign of $\beta-1$, which is negative because $\beta<1$. Thus, as one would expect, the real exchange rate always decreases when the foreign output becomes relatively larger, until it becomes optimal to import. The magnitude of $\beta$ determines how quickly the real exchange rate changes with $Q(t) / q(t)$. The greater the degree of risk aversion $(\eta)$ the smaller is $\beta$ and the greater is the change in the real exchange rate, for a given change in $Q(t) / q(t)$.

The change in the real exchange rate can be decomposed into the change in $P(t) / p(t)$ and the change in $S(t)$. When risk aversion is high $(\eta>1)$, both components move in the same direction, which produces a steep decline in the real exchange rate. This ensures a fast adjustment of the real exchange rate towards the value where imports become optimal, and corresponds to the case where the cone is relatively narrow. ${ }^{19}$ When, on the other hand, risk aversion is below unity, the nominal exchange rate increases without, however, dominating the drop in $P(t) / p(t)$ (because $\beta<1$ ). That is, the real exchange rate still drops when $Q(t) / q(t)$ rises. The slower decline of the real exchange rate also corresponds to the fact that the no-

\footnotetext{
${ }^{19}$ Note that $\kappa$ is a positive function of $\beta=\varepsilon(1-\eta)$. That is, the no-trade zone $1 / \kappa \leq Q(t) V q(t) \leq \kappa$ widens when risk-aversion $\eta$ falls. The intuition is that a high risk-aversion corresponds to a high aversion to consumption variability. Within the no-trade zone, consumption depends just on one output process, while there is diversification as soon as there is trade (see (A15, A16) in Appendix A). With infinite risk-aversion, the consumers would not heed the cost of shipping at all, and trade all the time. This corresponds to $k=1$ when $\eta=\infty$.
} 
trade region is relatively wider when risk-aversion is low.

We illustrate these implications of our model in Figures $2 a$ and $2 b$, which show the exchange rate and the bounds on it as functions of $Q(t) / q(t)$, when $m(t) / M(t)=1$. In Figure 2a, $\beta$ is positive, while it is negative in Figure $2 b$. Each graph is divided into the no-trade region, $1 / \kappa<Q / q<\kappa$, and the regions outside these bounds. First consider the price-parity function $p(t) / P(t)$ and the band around it. In the no-trade region, the commodity price parity function is the 45-degree line. This is because, with constant relative money supplies, we have $p(t) / P(t)$ $=C(t) / c(t)$, which equals $Q(t) / q(t)$ when there is no trade. In contrast, outside the no-trade region, $C(t) / c(t)$ is a constant, implying a flat price-parity line. The upper [lower] bound on the exchange rate then immediately follow by multiplying [dividing] $p(t) / P(t)$ by $(1+\tau)$. We now consider the exchange rate itself. In the region where $Q(t) / q(t)<1 / \kappa[>\kappa]$, the exchange rate is at the upper [lower] bound. In the no-trade region, however, the exchange rate $[Q(t) / q(t)]^{\beta}$ lies within the price band. It starts from the upper bound when $Q(t) / q(t)$ equals $1 / \kappa$, and approaches the lower bound as $Q(t) / q(t)$ approaches $\mathrm{K}$. Note that within the no-trade region the slope of the exchange rate is less steep than that of the price parity line, $p(t) / P(t)$. In Figure $2 a, \beta$ is positive: within the band, the exchange rate is a positive function of $Q(t) / q(t)$. In Figure $2 \mathrm{~b}$, the degree of relative risk aversion is larger than unity, implying a negative value for $\beta$. Compared to Figure $2 \mathrm{a}$, the no-trade region contracts. The concomitamt effect on the exchange rate is that within the no-trade region the nominal exchange rate is now a decreasing function of $Q(t) / q(t)$, which implies a steep decline in the real exchange rate.

In the next section, we discuss the implications of the above model for empirical tests of PPP.

\section{The Exchange Rate and its Relationship to the Price-Parity Rate}

In this section, we argue that, compared to the exchange rate model derived above, the traditional regression tests of PPP are mis-specified and have an omitted variables bias. 
The link between $S(t)$ and $(p(t), P(t))$ varies depending on whether or not there is trade. Within the no-trade zone, equation (17) describes the exchange rate as a function of $Q(t) / q(t)$, but we can easily obtain a proposition about the deviations from commodity price parity by substituting the relationships $q(t)=\varepsilon \nu m(t) / p(t)$ and $Q(t)=\varepsilon v M(t) / P(t)$ derived in (9). Thus, within the cone of no shipping,

$$
S(t)=\left[\frac{m(t)}{M(t)}\right]^{1-\beta}\left[\frac{P(t)}{P(t)}\right]^{\beta}, \quad \beta<1, \text { when } x(t)=0=X(t) .
$$

When trade is non-zero, the price-parity-bounds in (6) hold. This overall relationship is summed up in the following proposition:

Proposition 5: The relationship between exchange rates and traded goods prices is

$$
\ln S(t)= \begin{cases}(1-\beta) \ln \frac{m(t)}{M(t)}+\beta \ln \frac{p(t)}{P(t)}, \text { with } \beta<1, & \text { when } X(t)=0=x(t) ; \\ \ln (1+\tau)+\ln \frac{p(t)}{P(t)} & \text { when } X(t)>0 \\ -\ln (1+\tau)+\ln \frac{p(t)}{P(t)} & \text { when } x(t)>0\end{cases}
$$

Figure 3 shows $\ln S(t)$ as a function of $\ln \frac{p(t)}{P(t)}$, for $m(t) / M(t)=1$. The band for $\ln S(t)$ now is the 45-degree line plus or minus $\ln (1+\tau)$. For low [high] values of $\ln \frac{P(t)}{P(t)}, \ln S(t)$ is at the upper [lower] bound, while it gradually moves from the upper to the lower bound when $\ln \kappa<\ln \frac{P(t)}{P(t)}<\ln \kappa$. With risk-aversion below unity and, therefore, a positive $\beta$, this no-trade region is relatively wide, and $\ln S(t)$ is a positive function of $\ln \frac{p(t)}{P(t)}$ within this domain. An example with a positive $\beta$ is shown in Figure 3a. In Figure $3 b$, risk aversion is above unity, implying that $\beta$ is negative. This means that the no-trade domain contracts as compared to the previous case, and that within this domain the log exchange rate drops as $\ln \frac{P(t)}{P(t)}$ rises. $^{20}$

Proposition 5 has important implications for regression tests of relative PPP. The

\footnotetext{
${ }^{20}$ For instance, Apte, Kane and Sercu (1994) obtain eight negative coefficients out of 38 in their first-pass regressions. They ascribe this result to sampling error and downward errors-in-variables bias, but it is also consistent with a negative $\beta$ and frequent sampling within the band.
} 
traditional test equation for PPP is:

$$
\Delta \ln S_{t}(t)=\gamma_{0}+\gamma_{1} \Delta \ln \frac{p(t)}{P(t)}+e(t)
$$

In light of our model, such regressions are misspecified. First, the true model is a switch regression. Second, even within the band there is a missing variable. We shall discuss each issue separately.

First, equation (20) assumes a stable linear relationship between log exchange rate changes and inflation differentials (or changes in the log price-parity prediction). In contrast, our model (19) says that the relationship differs depending on whether the exchange rate is at the boundary of the no-trade region or not. In first-difference form, the exchange rate model derived in (19) implies that the appropriate regression model is of a switch-equation form:21

$$
\Delta \ln S(t)= \begin{cases}a_{01}+a_{11} \Delta \ln \frac{m(t)}{M(t)}+a_{21} \Delta \ln \frac{p(t)}{P(t)}+e_{1}(t) & \text { when } \frac{1}{\kappa}<\frac{Q(t)}{q(t)}<\kappa \\ a_{02}+a_{12} \Delta \ln \frac{p(t)}{P(t)}+e_{2}(t) & \text { when } \frac{Q(t)}{q(t)} \geq \kappa \\ a_{03}+a_{13} \Delta \ln \frac{p(t)}{P(t)}+e_{3}(t) & \text { when } \frac{Q(t)}{q(t)} \leq \frac{1}{\kappa}\end{cases}
$$

with, under the null hypothesis, $a_{01}=0=a_{02}=a_{03}, a_{11}=(1-\beta), a_{21}=\beta<1$, and $a_{12}=1=$ $a_{13}$. According to (21), if relative money supply is a constant (that is, abstracting from the missing variables bias), then

- if we sample two consecutive observations within the band, the first equation holds, which has an elasticity $\beta<1$ for the relative price. Thus, in the absence of biases created by the missing variable, $\Delta \ln \frac{m(t)}{M(t)}$, the true coefficient of $\Delta \ln \frac{p(t)}{P(t)}$ in equation (21) is $\beta<1$.

- for two consecutive observations at the lower [upper] bound, the second [third] equation of (21) holds. Both these equations have a unit elasticity for $p(t) / P(t)$. Thus, the true

\footnotetext{
${ }^{21}$ See Engel and Hamilton (1990), Hamilton (forthcoming) and Kaminsky (1993).
} 
coefficient of $\Delta \ln \frac{p(t)}{P(t)}$, for two consecutive observations at either boundary, is unity.

Forcing a single regression line through observations that are generated by different models will introduce biases. The slope coefficient $\gamma_{1}$ in the traditional regression test (20) estimates neither $\beta(<1)$, nor the true elasticity at the bound (which equals unity), but a mixture of the two.

Let us now abstract from the switch-regression aspect, and consider movements within the band only. In the no-trade region, the traditional test equation (20) suffers from a second problem: it omits a relevant variable, $\Delta \ln \frac{m(t)}{M(t)}$. This leads to a mis-specification and, as we shall argue, to an upward bias in $\gamma_{1}$ relative to $\beta$, especially under high inflation circumstances or in low-frequency data. The first equation in system (21) predicts that, within the band,

$$
\begin{gathered}
\mathrm{E}\left(\gamma_{1}\right) \equiv \frac{\operatorname{cov}\left[\Delta \ln S(t), \Delta \ln \frac{p(t)}{P(t)}\right]}{\operatorname{var}\left[\Delta \ln \frac{p(t)}{P(t)}\right] \cdot \cdots}=\frac{(1-\beta) \operatorname{cov}\left[\Delta \ln \frac{m(t)}{M(t)}, \Delta \ln \frac{P(t)}{P(t)}\right]+\beta \operatorname{var}\left[\Delta \ln \frac{p(t)}{P(t)}\right]}{\operatorname{var}\left[\Delta \ln \frac{p(t)}{P(t)}\right]} \\
=(1-\beta) \delta+\beta, \text { where } \delta=\frac{\operatorname{cov}\left[\Delta \ln \frac{m(t)}{M(t)}, \Delta \ln \frac{p(t)}{P(t)}\right]}{\operatorname{var}\left[\Delta \ln \frac{p(t)}{P(t)}\right]} .
\end{gathered}
$$

Note that the coefficient $\delta$ can be interpreted as the slope coefficient of the regression of $\Delta \ln \frac{m(t)}{M(t)}$ on $\Delta \ln \frac{p(t)}{P(t)}$. Thus, if $\delta$ is non-zero, the coefficient $\gamma_{1}$ contains not only $\beta$, the true effect of the regressor $\Delta \ln \frac{p(t)}{P(t)}$, but also (1- $\left.\beta\right)$, the effect of the omitted variable $\Delta \ln \frac{m(t)}{M(t)}$. To see the effect of the variability of relative money supply on $\delta$, use the fact that, within the band, $\Delta \ln \frac{p(t)}{P(t)}=\Delta \ln \frac{m(t)}{M(t)}-\Delta \ln \frac{q(t)}{Q(t)}$. This relationship allows us to rewrite $\delta$ as:

(23) $\delta \equiv \frac{\operatorname{cov}\left[\Delta \ln \frac{m(t)}{M(t)}, \Delta \ln \frac{p(t)}{P(t)}\right]}{\operatorname{var}\left[\Delta \ln \frac{p(t)}{P(t)}\right]}=\frac{\operatorname{var}\left[\Delta \ln \frac{m(t)}{M(t)}\right]-\operatorname{cov}\left[\Delta \ln \frac{m(t)}{M(t)}, \Delta \ln \frac{q(t)}{Q(t)}\right]}{\operatorname{var}\left[\Delta \ln \frac{m(t)}{M(t)}\right]-2 \operatorname{cov}\left[\Delta \ln \frac{m(t)}{M(t)}, \Delta \ln \frac{q(t)}{Q(t)}\right]+\operatorname{var}\left[\Delta \ln \frac{q(t)}{Q(t)}\right]}$

When $\operatorname{var}\left[\Delta \ln \frac{m(t)}{M(t)}\right]=0$, the covariance term on the right hand side is also zero, and $\delta$ therefore equals zero. The coefficient $\delta$ is equal to 0.5 when the variance of relative money supply equals the variance of relative output. Finally, when $\operatorname{var}\left[\Delta \ln \frac{m(t)}{M(t)}\right]$ becomes very large 
relative to $\operatorname{var}\left[\Delta \ln \frac{Q(t)}{Q(t)}\right], \delta$ approaches unity. Given that $\mathrm{E}\left(\gamma_{1}\right)=\beta+(1-\beta) \delta$, it then follows that large variations in relative money growth rates lead to an expected value for $\gamma_{1}$ that approaches unity, even if $\beta$ is substantially below unity, simply because $\delta$ approaches unity. In short, under hyperinflation, the regressor $\Delta \ln \frac{p(t)}{P(t)}$ of the PPP test equation tracks almost perfectly the omitted variable, $\Delta \ln \frac{m(t)}{M(t)}$, and adds the effect $(1-\beta)$ of this omitted variable to the effect $\beta$ of the price change. Thus, the empirical link between prices and the exchange rate is close to unity under hyperinflation circumstances as found, for example, by McNown and Wallace (1989).

A similar argument can be invoked to explain why tests that use low-frequency data generally produce estimates of $\gamma_{1}$ closer to unity than do tests using short observation intervals. Thus far we assumed that, holding constant the outputs, any change in money supply immediately feeds through into prices. In practice, however, in the short-term the effect of changes in money supply on prices is rather weak and $\delta$ is close to zero. This implies that, with high-frequency data $\gamma_{1}$ measures essentially $\beta$ (which is below unity) as long as we sample within the band. Over longer intervals, however, the prices become increasingly more correlated with $\Delta \ln \frac{m(t)}{M(t)}$; so $\delta$ becomes larger, and $E\left(\gamma_{1}\right)=\beta+(1-\beta) \delta$ picks up more of the money-supply effect, (1- $\beta$ ). Thus, for low-frequency data the expected value of $\gamma_{1}$ is closer to unity even within the cone.

\section{Conclusion}

We construct a two country model where each country is endowed with a non-traded good and a (risky) homogenous tradeable good. The endowment of the tradeable good is stochastic while that of the on-traded good is riskless. We introduce a cost for transferring this tradeable good from one country to another. As a consequence of this cost, there is a no-trade region within which it is optimal not to correct an imbalance between the quantities of the tradeable good in the two countries. As long as the exchange rate is in the no-trade region and money supply effects are controlled for, the elasticity of the exchange rate with respect to the relative prices of tradeable goods is below unity, and arguably even negative. 
We therefore argue that the low regression coefficients, commonly found when changes of exchange rates are regressed on inflation differentials, reflect to some extent a true relationship rather than just being the result of errors-in-variables. The model also implies that pure inflation (not reflecting changes in relative scarcities) should have a proportional effect on the actual exchange rate and on the price bounds. When the ratio of traded goods prices and relative money supplies are strongly correlated, as is the case during hyperinflation episodes, the inflation differential picks up the effect of the omitted factor, relative money supplies, and leads to an increase in the regression slope. A similar effect can be expected when the observation interval is increased. 


\section{Appendix A: The Central Planner's Problem}

\section{Proof of Proposition 1}

Following Dumas (1992), we identify the optimal consumption rule $[c(t), C(t)]$ and shipping rule $[x(t), X(t)]$ using a central planner's perspective. It will be shown later that the central planner's cone is the same as that obtained by solving the decentralized problem. The central planner's problem is to maximize the aggregate utility of the two countries, weighted by $\lambda^{*}$ and $1-\lambda^{*}$ :

$$
\operatorname{Max} \lambda^{*} \mathrm{E} \int_{0}^{\infty} \frac{\left[c(t)^{\varepsilon} c^{\prime}(t)^{(1-\varepsilon)}\right]^{1-\eta}}{1-\eta} \mathrm{d} t+\left(1-\lambda^{*}\right) \mathrm{E} \int_{0}^{\infty} \frac{\left[C(t)^{\varepsilon} C^{\prime}(t)^{(1-\varepsilon)}\right]^{1-\eta}}{1-\eta} \mathrm{d} t
$$

s.t.

$$
\begin{gathered}
c(t)=q(t)-x(t)+\frac{X(t)}{1+\tau} \\
C(t)=Q(t)-X(t)+\frac{x(t)}{1+\tau} \\
x(t) \geq 0, X(t) \geq 0, c^{\prime}(t)=q^{\prime}(t), C^{\prime}(t)=Q^{\prime}(t)
\end{gathered}
$$

Given that the utility function is time-separable and that the constraints apply period by period, we can rewrite the intertemporal problem as a static (period-by-period) problem. To simplify the notation, set $\beta=\varepsilon(1-\eta)$ and $\lambda(t)=\frac{\lambda^{*} q^{\prime}(t)^{(1-\varepsilon)(1-\eta)}}{\lambda^{*} q^{\prime}(t)^{(1-\varepsilon)(1-\eta)}+\left(1-\lambda^{*}\right) Q^{\prime}(t)^{(1-\varepsilon)(1-\eta)}} .22$ The static problem of the central planner then is

$$
\operatorname{Max} \lambda(t) c(t)^{\beta}+(1-\lambda(t)) C(t)^{\beta}
$$

s.t.

$$
c(t)=q(t)-x(t)+\frac{X(t)}{1+\tau}, C(t)=Q(t)-X(t)+\frac{x(t)}{1+\tau}
$$

\footnotetext{
${ }^{22}$ This is a deterministic variable. It is constant when $Q^{\prime}(t) / q^{\prime}(t)$ is constant, and it equals .5 when $Q^{\prime}(t)=q^{\prime}(t)$
} and $\lambda^{*}=1-\lambda^{*}$ (the 'equal countries' case). 


$$
x(t) \geq 0, X(t) \geq 0
$$

Write the Lagrangian:

$$
£=\lambda(t) c(t)^{\beta}+(1-\lambda(t)) C(t)^{\beta}+\theta_{1}(t)\left[q(t)-x(t)+\frac{X(t)}{1+\tau}-c(t)\right]+\theta_{2}(t)\left[Q(t)-X(t)+\frac{x(t)}{1+\tau}-C(t)\right]
$$

The first-order conditions are

$$
\begin{gathered}
0=\frac{\partial £}{\partial c(t)}=\lambda(t) \beta c(t)^{\beta-1}-\theta_{1}(t) \Rightarrow \lambda(t) \beta c(t)^{\beta-1}=\theta_{1}(t) \\
0=\frac{\partial £}{\partial C(t)}=(1-\lambda(t)) \beta C\left(t^{\beta-1}-\theta_{2}(t) \Rightarrow(1-\lambda(t)) \beta C(t)^{\beta-1}=\theta_{2}(t)\right. \\
0=x(t) \frac{\partial £}{\partial x(t)}
\end{gathered}
$$

$$
0 \geq \frac{\partial £}{\partial x(t)}=-\theta_{1}(t)+\frac{\theta_{2}(t)}{1+\tau} \Rightarrow \frac{\theta_{1}(t)}{\theta_{2}(t)} \geq \frac{1}{1+\tau}
$$

$$
0=X(t) \frac{\partial E}{\partial X(t)}
$$

$$
0 \geq \frac{\partial £}{\partial X(t)}=\frac{\theta_{1}(t)}{1+\tau}-\theta_{2}(t) \Rightarrow \frac{\theta_{1}(t)}{\theta_{2}(t)} \leq 1+\tau
$$

(A6) and (A8) imply that

$$
\frac{1}{1+\tau} \leq \frac{\theta_{1}(t)}{\theta_{2}(t)} \leq 1+\tau
$$

Dividing (A3) by (A4), and using (A9), we then have

$$
\frac{1}{1+\tau} \leq \frac{\lambda(t)}{1-\lambda(t)}\left[\frac{c(t)}{C(t)}\right]^{\beta-1} \leq 1+\tau
$$

Thus, we obtain a cone for consumption:

$$
\kappa_{2}(t)=\left[\frac{1-\lambda(t)}{\lambda(t)(1+\tau)}\right]^{1 /(1-\beta)} \leq \frac{C(t)}{c(t)} \leq\left[\frac{(1+\tau)(1-\lambda(t))}{\lambda(t)}\right]^{1 /(1-\beta)}=\kappa_{1}(t)
$$


Note that the $\kappa_{\mathrm{i}}(t)$ 's are deterministic, but not constant if the ratio $q^{\prime}(t) / Q^{\prime}(t)$ changes. When the setup is fully symmetric (i.e. $\lambda^{*}=1-\lambda^{*}$ and $q^{\prime}(t)=Q^{\prime}(t)$ ), then $\lambda(t)$ equals $1-\lambda(t)$, and we obtain the symmetric, time-invariant cone where $\kappa_{1}(t)=\kappa$ and $\kappa_{2}(t)=1 / \kappa$ :

$$
\frac{1}{\kappa} \leq \frac{C(t)}{C(t)} \leq \kappa \equiv(1+\tau)^{1 /(1-\beta)}
$$

We now characterize the solution in each of the following regions: $\mathrm{i}$ ) $x(t)=0=X(t)$ (no trade); ii) $x(t)>0$ and $X(t)=0$ (exports from the home country); and ii) $X(t)>0$ and $x(t)=0$ (exports from the foreign country).

i) No Trade. With zero trade, $c(t)=q(t)$ and $C(t)=Q(t)$. Substituting these equalities into (A11), we obtain the bounds on the values of $Q(t) / q(t)$ that are consistent with no trade:

$$
\kappa_{2}(t)=\left[\frac{1-\lambda(t)}{\lambda(t)(1+\tau)}\right]^{1 /(1-\beta)} \leq \frac{Q(t)}{q(t)} \leq\left[\frac{(1+\tau)(1-\lambda(t))}{\lambda(t)}\right]^{1 /(1-\beta)}=\kappa_{1}(t)
$$

ii) Exports. If $x(t)>0$ and $X(t)=0,(\mathrm{~A} 5)$ and (A6) imply that $\frac{\theta_{1}}{\theta_{2}}=\frac{1}{1+\tau}$. Relation (A11) then implies that consumption is on the cone:

$$
\frac{C(t)}{c(t)}=\kappa_{2}(t)
$$

which, together with $c(t)=q(t)-x(t)$ and $C(t)=Q(t)+\frac{x(t)}{1+\tau}$, yields

$$
\begin{gathered}
c(t)=\frac{(1+\tau) Q(t)+q(t)}{(1+\tau) \kappa_{2}(t)+1} \\
C(t)=\kappa_{2} \frac{(1+\tau) Q(t)+q(t)}{(1+\tau) \kappa_{2}(t)+1} \\
x(t)=(1+\tau) \frac{\kappa_{2}(t) q(t)-Q(t)}{(1+\tau) \kappa_{2}(t)+1}
\end{gathered}
$$

iii) Imports. The case where $X(t)>0$ and $x(t)=0$ is fully symmetric to the case of exports considered above: interchange $Q$ and $q$, and $C$ and $c$; and substitute $X$ for $x$, and $\kappa_{1}$ for $\kappa_{2}$ to obtain the solution. 


\section{Appendix B: The Solution for $S(t)$}

\section{Proof of Proposition 3}

We use the consumption CAPM (CCAPM) to identify the risk-adjusted drift in the standard no-arbitrage differential equation. Breeden $(1979$, equations $(32,33))$ shows that, in a model with more than one good and with uncertain inflation, optimal consumption and investment decisions induce two price indices in the CCAPM, one based on the average consumption budget shares and one on the marginal consumption budget shares. When the commodity preference function $u\left(c(t), c^{\prime}(t)\right)$ is homothetic, all 'income elasticities' are equal to unity, and the two price indices become identical. The utility function $u\left(c(t), c^{\prime}(t)\right)=c(t)^{\varepsilon} c^{\prime}(t)^{1-\varepsilon}$ belongs to this class. The unique price index is $\pi(t)$, as defined in Proposition 2, and this index is associated with a consumption quantity $\chi(t)$ defined in units of a composite good. In short, with homothetic commodity preferences, "the" real unit of consumption is welldefined, just like in a one-good setting (see also Samuelson and Swamy (1974)).

Optimal consumption and investment decisions then imply a standard consumption CAPM expressed in this real unit: the expected real return $E\left(\frac{d Y(t)}{Y(t)}\right)$ on any asset in excess of the real zero-beta rate $\zeta(t)$ equals relative risk aversion, $\eta$, times the covariance of the asset's real return with the percentage change in the (composite) consumption quantity $\chi(t)$. That is,

$$
E\left(\frac{d Y(t)}{Y(t)}\right)-\zeta(t) d t=\eta \frac{d Y(t)}{Y(t)} \frac{d \chi(t)}{\chi(t)}
$$

We now translate these real returns into returns expressed in units of the non-traded good. If we go from real units to any other numeraire, we can link the real price $Y(t)$ to the nominal price $y(t)$ and the price index $i(t)$ via $Y(t)=y(t) / i(t)$. Ito's Lemma then implies

$$
\frac{\mathrm{d} Y(t)}{Y(t)}=\frac{\mathrm{d} y(t)}{y(t)}-\frac{\mathrm{d} i(t)}{i(t)}-\frac{\mathrm{d} y(t)}{y(t)} \frac{\mathrm{d} i(t)}{i(t)}+\left[\frac{\mathrm{d} i(t)}{i(t)}\right]^{2}
$$

and 


$$
\eta \frac{\mathrm{d} Y(t)}{Y(t)} \frac{\mathrm{d} \chi(t)}{\chi(t)}=\eta\left[\frac{\mathrm{d} y(t)}{y(t)}-\frac{\mathrm{d} i(t)}{i(t)}\right] \frac{\mathrm{d} \chi(t)}{\chi(t)}
$$

Our chosen unit of account being the non-tradeable good, our price index $i(t)$ is the price of the unit composite good expressed in currency units, $\pi(t)$, deflated by the price of the non-tradeable good expressed in currency units, $p(t): i(t)=\pi(t) / p^{\prime}(t)$. From equation (8), this is proportional to $\left[p(t) / p^{\prime}(t)\right]^{\varepsilon}$ :

$$
i(t)=\frac{\pi(t)}{p^{\prime}(t)}=\frac{\varepsilon^{-\varepsilon}(1-\varepsilon)^{\varepsilon-1} p(t)^{\varepsilon} p^{\prime}(t)^{1-\varepsilon}}{p^{\prime}(t)}=\varepsilon^{-\varepsilon}(1-\varepsilon)^{\varepsilon-1}\left[\frac{p(t)}{p^{\prime}(t)}\right]^{\varepsilon}
$$

Thus, the inflation rate $\frac{d i(t)}{i(t)}$ is $\varepsilon \frac{d\left(p(t) / p^{\prime}(t)\right)}{p(t) p^{\prime}(t)}$. The CCAPM in units of the non-traded good therefore is (where $y(t)$ are the prices expressed in units of the non-traded good):

$$
\begin{gathered}
\mathrm{E}\left(\frac{\mathrm{d} y(t)}{y(t)}\right)-\mathrm{E}\left[\varepsilon \frac{\mathrm{d}\left(p(t) / p^{\prime}(t)\right)}{p(t) / p^{\prime}(t)}\right]-\left[\varepsilon \frac{\mathrm{d}\left(p(t) / p^{\prime}(t)\right)}{p(t) / p^{\prime}(t)}\right] \frac{\mathrm{d} y(t)}{y(t)}+\left[\varepsilon \frac{\mathrm{d}\left(p(t) / p^{\prime}(t)\right)}{p(t) / p^{\prime}(t)}\right]^{2}-\zeta(t) \mathrm{d} t \\
=\eta\left[\frac{\mathrm{d} y(t)}{y(t)}-\varepsilon \frac{\mathrm{d}\left(p(t) / p^{\prime}(t)\right)}{p / p^{\prime}}\right] \frac{\mathrm{d} \chi(t)}{\chi(t)}
\end{gathered}
$$

To obtain the differential equation for $Z(t)$, we now apply (B2) to two particular assets. The first is the domestic asset with a return that is risk-free in terms of the domestic nontraded good. When the return $\frac{d y(t)}{y(t)}$ equals $\phi \mathrm{d} t$ without risk, the covariance with inflation and with consumption growth is zero, and (B2) simplifies to

$$
\phi \mathrm{d} t-E\left[\varepsilon \frac{\mathrm{d}\left(p(t) / p^{\prime}(t)\right)}{p(t) / p^{\prime}(t)}\right]+\left[\varepsilon \frac{\mathrm{d}\left(p(t) / p^{\prime}(t)\right)}{p(t) / p^{\prime}(t)}\right]^{2}-\zeta(t) \mathrm{d} t=\eta\left[-\varepsilon \frac{\mathrm{d}\left(p(t) / p^{\prime}(t)\right)}{p(t) / p^{\prime}(t)} \frac{\mathrm{d} \chi(t)}{\chi(t)}\right]
$$

The second asset of interest to us is the foreign asset with a return which is risk-free in terms of the foreign nontraded good. In terms of the domestic nontraded good, the return on this asset is $\frac{\mathrm{dy}(t)}{y(t)}=\frac{\mathrm{d} Z(t)}{\mathrm{Z}(t)}+\phi \mathrm{d} t,{ }^{23}$ implying

(B4) $E\left(\frac{\mathrm{d} Z(t)}{Z(t)}\right)+\phi \mathrm{d} t-\mathrm{E}\left(\varepsilon \frac{\mathrm{d}\left(p(t) / p^{\prime}(t)\right)}{p(t) / p^{\prime}(t)}\right)-\left[\varepsilon \frac{\mathrm{d}\left(p(t) / p^{\prime}(t)\right)}{p(t) / p^{\prime}(t)}\right] \frac{\mathrm{d} Z(t)}{Z(t)}+\left[\varepsilon \frac{\mathrm{d}\left(p(t) / p^{\prime}(t)\right)}{p(t) / p^{\prime}(t)}\right]^{2}-\zeta(t) \mathrm{d} t$

\footnotetext{
${ }^{23}$ The rate $\phi$ is in units of the non-traded good: in each country there is an asset that provides a known output of non-traded goods, and the technology is common to both countries. Thus, the interest rates we restrict are these 'real' rates, not the nominal interest rates. In fact, both nominal rates will differ, reflecting expected money growth and risk of money growth.
} 


$$
=\eta\left[\frac{\mathrm{dZ}(t)}{Z(t)}-\varepsilon \frac{\mathrm{d}\left(p(t) / p^{\prime}(t)\right)}{p / p^{\prime}}\right] \frac{\mathrm{d} \chi(t)}{\chi(t)}
$$

Subtracting (B3) from (B4), we get

$$
\mathrm{E}\left(\frac{\mathrm{d} Z(t)}{Z(t)}\right)-\varepsilon \frac{\mathrm{d}\left(p(t) / p^{\prime}(t)\right)}{p(t) / p^{\prime}(t)} \frac{\mathrm{d} Z(t)}{Z(t)}=\eta \frac{\mathrm{d} Z(t)}{Z(t)} \frac{\mathrm{d} \chi(t)}{\chi(t)}
$$

or, after multiplying by $Z(t)$ and rearranging,

$$
\mathrm{E}(\mathrm{d} Z(t))=\left[\varepsilon \frac{\mathrm{d}\left(p(t) / p^{\prime}(t)\right)}{p(t) / p^{\prime}(t)}+\eta \frac{\mathrm{d} \chi(t)}{\chi(t)}\right] \mathrm{d} Z(t)
$$

Given our assumptions of lognormal processes for $Q(t)$ and $q(t)$, constant relative risk aversion preferences, and proportional transactions costs, we can specialize $Z(t)$ as a function of the relative output: $Z(t)=Z(Q(t) / q(t))$. We then use Ito's Lemma to expand $E(d Z(t))$, noting that the mean and variance of $Q(t) \vee q(t)$ are given by $\left[\mu-\mu-k \sigma^{2}+\sigma^{2}\right]=\sigma^{2}(1-k)$ and $\left[\sigma^{2}-2 k \sigma^{2}+\sigma^{2}\right]=2 \sigma^{2}(1-k)$, respectively. Finally, because consumption of the nontradeable good is deterministic, we can use

$$
\mathrm{d} Z(t) \frac{\mathrm{d} \chi(t)}{\chi(t)}=\mathrm{d} Z(t) \varepsilon \frac{\mathrm{d} c(t)}{c(t)}=\varepsilon Z^{\prime} \mathrm{d}\left[\frac{Q(t)}{q(t)}\right] \frac{\mathrm{d} c(t)}{c(t)}
$$

and likewise, from the demand equations (9),

$$
\mathrm{d} Z(t) \frac{\mathrm{d}\left(p(t) / p^{\prime}(t)\right)}{p(t) / p^{\prime}(t)}=-\mathrm{d} Z(t) \frac{\mathrm{d} c(t)}{c(t)}=Z^{\prime} \mathrm{d}\left[\frac{Q(t)}{q(t)}\right] \frac{\mathrm{d} c(t)}{c(t)}
$$

Then (B5) can be rewritten as

$$
Z^{\prime}\left[\frac{Q(t)}{q(t)}\right]\left[\sigma^{2}(1-k)\right] \mathrm{d} t+Z^{\prime \prime}\left[\frac{Q(t)}{q(t)}\right]^{2}\left[\sigma^{2}(1-k)\right] \mathrm{d} t=\varepsilon(\eta-1) Z^{\prime} \mathrm{d}\left[\frac{Q(t)}{q(t)}\right] \frac{\mathrm{d} c(t)}{c(t)}
$$

or

$$
Z^{\prime}\left[\frac{Q(t)}{q(t)}\right] \alpha(t)+\frac{1}{2} Z^{\prime \prime}\left[\frac{Q(t)}{q(t)}\right]^{2} \delta^{2}=0
$$

where $\alpha(t)$ and $\delta^{2}$ are the risk-adjusted mean and variance of $\frac{d(Q(t) \vee q(t))}{Q(t) \gamma q(t)}$, respectively: $\alpha(t)=\sigma^{2}(1-k)-\varepsilon(\eta-1) \frac{\mathrm{d}(Q(t) / q(t))}{Q(t) / q(t)} \frac{\mathrm{d} c(t)}{c(t)} \frac{1}{\mathrm{~d} t} \quad$ and $\delta^{2}=2 \sigma^{2}(1-k)$. 


\section{Proof of Proposition 4.}

Within the no-trade zone, $c(t)=q(t)$. In this case, the risk-adjusted mean becomes a constant:

$$
\begin{gathered}
\alpha(t)=\sigma^{2}(1-k)-\varepsilon(\eta-1) \frac{\mathrm{d}(Q(t) / q(t))}{Q(t) / q(t)} \frac{\mathrm{d} q(t)}{q(t)} \frac{1}{\mathrm{~d} t} \\
=\sigma^{2}(1-k)-\varepsilon(\eta-1)\left[\frac{\mathrm{d} Q(t)}{Q(t)}-\frac{\mathrm{d} q(t)}{q(t)}+\ldots\right] \frac{\mathrm{d} q(t)}{q(t)} \frac{1}{\mathrm{~d} t}=\sigma^{2}(1-k)-\varepsilon(\eta-1) \sigma^{2}(k-1) \\
=[1+\varepsilon(\eta-1)] \sigma^{2}(1-k)
\end{gathered}
$$

The general solution of the differential equation in (B6) is

$$
\begin{gathered}
Z(t)=d_{1}\left[\frac{Q(t)}{q(t)}\right]^{\beta_{1}}+d_{2}\left[\frac{Q(t)}{q(t)}\right]^{\beta_{2}} \\
\beta=\left(\frac{1}{2}-\frac{\alpha}{\delta^{2}}\right) \pm \sqrt{\left(\frac{1}{2}-\frac{\alpha}{\delta^{2}}\right)^{2}}=\left\{\begin{array}{c}
0 \\
\varepsilon(1-\eta)
\end{array}\right.
\end{gathered}
$$

Since the inverse of $Z(t)$ is also an exchange rate, it must be of the same mathematical form as $Z(t)$ itself, which implies that either $d_{1}=0$ or $d_{2}=0: 24$

$$
Z(t)=d\left[\frac{Q(t)}{q(t)}\right]^{\beta} \quad, \quad \beta=\varepsilon(1-\eta) \text { or } 0 .
$$

Equation (B9) has two unknowns, $d$ and $k$, to be determined from (12):

$$
\begin{array}{lr}
\text { when } Q(t) / q(t)=\kappa: & Z(\kappa)=d \kappa^{\beta}=\frac{\kappa}{1+\tau^{*}} \\
\text { when } Q(t) / q(t)=\frac{1}{\kappa}: & Z\left(\frac{1}{\kappa}\right)=d\left(\frac{1}{\kappa}\right) \beta=\frac{1+\tau}{\kappa}
\end{array}
$$

${ }^{24}$ It is easily checked that (B9) is consistent with valuation in terms of the other numeraire. Define $A(t)=1 / Z(t)$ $=$ the exchange rate as viewed by the other country, and assume $A(t)=A(Q(t) / q(t))$. The risk-adjusted mean for the exchange rate measured in units of the foreign non-traded good is similar to the reference-country riskadjusted mean $\alpha$ (see (B6)) except that foreign consumption $C(t)$ replaces home consumption $c(t)$. It is simple (albeit tedious) to show that this leads to the same solution as $(16): A(t)=(Q(t) / q(t))^{B}$ where B equals either $\varepsilon(1-\eta)$ or zero, i.e. $B=-\beta$ as it should. 
In addition, we have to identify the correct root of $\beta$. When $\beta$ equals zero, there is no solution for the above system unless $1+\tau=\kappa$, an implication that is not compatible with the central planner's solution unless $\eta=1$. Alternatively, assume that $\beta=\varepsilon(1-\eta)$. Solving the two equations for $d$ and $\kappa$ under this hypothesis, we find:

$$
\begin{gathered}
\kappa=(1+\tau)^{1 /(1-\beta)} \\
d=1
\end{gathered}
$$

This solution of $\mathrm{K}$ is the same as that obtained from solving the central planner's problem, (A12), which confirms that $\beta=\varepsilon(1-\eta)$ is the correct root.

\section{Value Matching and Smooth Pasting}

From Proposition 2, when $Q(t), q(t)<1 / \kappa, S(t)$ is give by:

$$
S(t)=\frac{m(t)}{M(t)} \frac{1+\tau}{\mathrm{K}} \text { when } Q(t) /(t) \leq 1 / \mathrm{K}
$$

We now show that this exchange rate satisfies the value-matching and smooth-pasting conditions. The value matching condition says that the value before and after shipping must be the same, otherwise there is an arbitrage opportunity. Following Dumas (1992), we can write this condition as

$$
0=\Delta S(Q(t), q(t))=S\left(q(t)-\mathrm{d} x(t), Q(t)+\frac{\mathrm{d} x(t)}{1+\tau}\right)-S(Q(t), q(t))
$$

$$
\begin{gathered}
0=S\left(q(t)-\mathrm{d} x(t), Q+\frac{\mathrm{d} x(t)}{1+\tau}\right)-S(q(t)-\mathrm{d} x(t), Q(t))+S(q(t)-\mathrm{d} x(t), Q(t))-S(Q(t), q(t)) \\
0=\frac{S Q}{1+\tau}-S_{q}
\end{gathered}
$$

where $S_{Q}$ and $S_{q}$ are partial derivatives with respect to $Q(t)$ or $q(t)$ separately. We now apply this to $S(t)$ written as a function of relative output, $S(Q(t) / q(t))$. Defining $S^{\prime}$ and $S^{\prime \prime}$ as the derivatives w.r.t. $[Q(t) / q(t)]$ ), and using $S_{q}=S^{\prime} \frac{-Q(t)}{q\left(t^{2}\right.}$ and $S_{Q}=S^{\prime} \frac{1}{q(t)}$, the value matching condition can be written as 


$$
0=S^{\prime} \frac{1}{(1+\tau) q(t)}-S^{\prime} \frac{-Q(t)}{q(t)^{2}}=\frac{-S^{\prime}}{q(t)}\left[\frac{1}{1+\tau}+\frac{Q(t)}{q(t)}\right]
$$

or, simply,

$$
S^{\prime}=0
$$

Thus, as we move from $Q(t) / q(t)=1 / \kappa$ to a lower output ratio, value matching requires that the derivative of $S(t)$ with respect to $(Q(t) / q(t))$ should be zero. This condition is satisfied by the solution in the zone of exports, (B12), which is independent of $Q(t)$ and $q(t)$.

The smooth-pasting condition says that $S^{\prime}$ should be the same before and after shipping. By analogy with (B13), we can write this as

$$
0=\Delta S_{q}=S_{q q}(t)-\frac{1}{1+\tau} S_{q Q}(t)
$$

For $S$ as a function of $(Q(t) / q(t))$, we use $S_{q q}(t)=\frac{2 Q(t)}{q(t)^{3}} S^{\prime}+\frac{-Q(t)}{q(t)^{2}} S^{\prime \prime} \frac{-Q(t)}{q(t)^{2}}$ and $S_{q Q^{\prime}}(t)=-\frac{1}{q(t)^{2}}$ $S^{\prime}+\frac{-Q(t)}{q(t)^{2}} S^{\prime \prime} \frac{1}{q(t)}$, and obtain

$$
\begin{aligned}
0 & =\frac{2 Q(t)}{q(t)^{3}} S^{\prime}+\left[\frac{Q(t)}{q(t)^{2}}\right]^{2} S^{\prime \prime}-\frac{-1}{1+\tau}\left[\frac{1}{q(t)^{2}} S^{\prime}+\frac{Q(t)}{q(t)^{3}} S^{\prime \prime}\right] \\
& =S^{\prime}\left[\frac{2 Q(t)}{q(t)^{3}}+\frac{1}{q(t)^{2}(1+\tau)}\right]+S^{\prime \prime}\left[\frac{Q(t)^{2}}{q(t)^{4}}+\frac{Q(t)}{q(t)^{3}(1+\tau)}\right]
\end{aligned}
$$

As $S^{\prime}=0$, this implies that

$$
S^{\prime \prime}=0
$$

Thus, smooth pasting requires that the left second derivative of $S(t)$ with respect to $Q(t) / q(t)$ should be zero. This condition is also satisfied by $S(t)=\frac{m(t)}{M(t)} \frac{1+\tau}{\kappa}$. The analysis at the other boundary is analogous. 


\section{Index to Notation}

Arranged alphabetically; foreign quantities are given by the equivalent upper-case characters

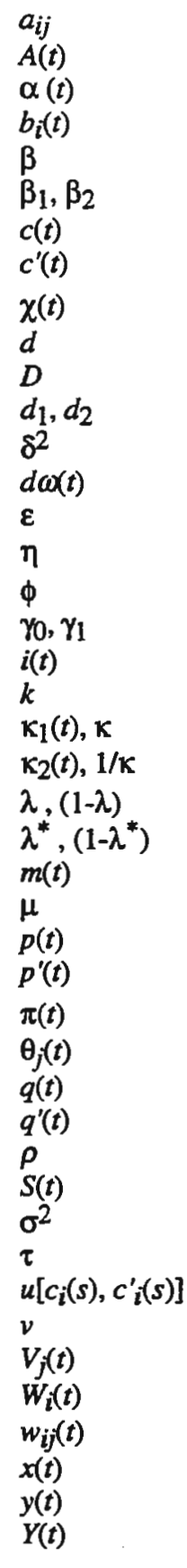

coefficients of relative prices in regression tests of PPP based on our model

$=1 / Z(t)$

the risk-adjusted drift of the percentage changes in $Q(t) / q(t)$,

the domestic agent's rate of nominal consumption expenditure

coefficient of $Q(t) / q(t)$ in the particular solution of the exchange rate

coefficients of $Q(t) / q(t)$ in the general solution of the exchange rate

the home investor's rate of consumption of the tradeable good

the home investor's rate of consumption of the non-traded good

$=c(t)^{\varepsilon} c^{\prime}(t)^{1-\varepsilon}=$ the rate of consumption of the composite good

constant in the particular solution of the exchange rate from domestic view constant in particular solution of the exchange rate, from foreign viewpoint constants in the general solution of the exchange rate

$=2 \sigma^{2}(1-k)$, the variance of the percentage changes in $Q(t) / q(t)$

random white noise affecting the production of the domestic tradeable good the coefficient of the tradeable goods consumption in agent's preferences

$=-\chi \mathrm{u}_{\chi \chi} / \mathrm{u}_{\chi}=$ degree of relative risk aversion

the drift of the risk-free endowment process in the non-traded good sector constant and slope coefficient in standard regression tests of PPP

general price index symbol; $i(t)=\pi(t) / p^{\prime}(t)$ in Appendix B

correlation coefficient between $d \omega(t)$ and $d \Omega(t)$

slope of the upper ray of the cone of no-shipping

slope of the lower ray of the cone of no-shipping

$\propto \lambda^{*} q^{\prime}(t),\left(1-\lambda^{*}\right) Q^{\prime}(t)$ rescaled so as to sum to unity

weight of home (foreign) utility in central planner's objective function.

the quantity of base money at home

instantaneous mean of the endowment process of the tradeable good

nominal price of the domestic tradeable good in terms of domestic currency nominal price of domestic non-traded good in terms of domestic currency

$=\varepsilon^{-\varepsilon}(1-\varepsilon)^{\varepsilon-1} p(t)^{\varepsilon} p^{\prime}(t)^{1-\varepsilon}=$ price of one unit of the composite good

Lagrangian multiplier for constraint $j$ in the central planner's problem rate of output of the tradeable good at home at time $t$

rate of output of the non-traded good at home at time $t$

subjective discount rate

nominal exchange rate (nominal value of one unit of foreign currency)

instantaneous variance of the endowment process of the tradeable good

proportional transaction cost for transferring goods between countries

the domestic investor's utility function

velocity of money

nominal (home currency) value of asset $j$

domestic investor $i$ 's nominal wealth (in domestic currency units)

weight of asset $j$ in $i$ 's portfolio

rate of (gross) exports of the tradeable good from home to foreign country real price, in units of the home country's non-traded good, of an asset real price, in units of the home country's composite commodity, of an asset $=S(t) \frac{p^{\prime}(t)}{p(t)}$, the exchange rate when the non-traded goods are used as numeraires in each country. 


\section{References}

Abuaf, A. and P. Jorion (1990): Purchasing Power Parity in the Long Run, Journal of Finance, 45, 157-174.

Adler, M., and B. Dumas (1983): International Portfolio Choice and Corporation Finance: A Synthesis, Journal of Finance, 38, 925-984.

Adler, M., and B. Lehman (1983): Deviations from PPP in the Long Run, Journal of Finance, 38, 1471-1487.

Apte, P., M. Kane, and P. Sercu (1994): Evidence of Relative Purchasing Power in the Medium Run, forthcoming in Journal of International Money and Finance.

Baillie, R. T. and D. D. Selover (1987): Cointegration and Model of Exchange Rate Determination, International Journal of Forecasting, 3, 43-51.

Benninga, S., and A. Protopapadakis (1988): The Equilibrium Pricing of Exchange Rates and Assets When Trade Takes Time, Journal of International Money and Finance, 7(2), 361-374.

Betton, S, M. D. Levi, and R. Uppal (1992) Index-Induced Errors and Purchasing Power Parity: Bounding the Bias, Working Paper, UBC, Vancouver.

Black, F. (1973): Transportation Costs, Tariffs, and Taxes in a One-sector Model of Trade, Working Paper, M.I.T.

and M. Scholes (1972), The Valuation of Option Contracts and a Test of Market Efficiency, Journal of Finance, 27(2), 399-417.

Cassel, G. (1918): Abnormal Deviations in International Exchanges, Economic Journal, 413415.

Corbae, D., and D. Ouliaris (1988): Cointegration and Model of Exchange Rate Determination, Review of Economics and Statistics, 70, 508-511.

Cornell, B. (1979): Relative Price Changes and Deviations from Purchasing Power Parity, Journal of Banking and Finance, 3(3), 263-280.

Cumby, R. and M. Obstfeld (1984): International Interest Rate and Price Level Linkages under Flexible Exchange Rates: A Review of Recent Evidence, in Exchange Rate Theory and Practice, eds. J. Bilson and R. Marston, University of Chicago Press, Chicago, 121-151.

Davis, M. and A. Norman (1990): Portfolio Selection with Transaction Costs, Mathematics of Operations Research, 15(4), 676-713.

Dumas, B.(1992): Dynamic Equilibrium and the Real Exchange Rate in a Spatially Separated World, The Review of Financial Studies, 5(2), 153-180.

Enders, W. (1988): ARIMA and Cointegration Tests of PPP under Fixed and Flexible Exchange Rate Regimes, Review of Economics and Statistics, 70, 504-508.

Engel, C. and J. Hamilton (1990): Long Swings inthe dollar: Are They in the Data and Do Markets Know It?, American Economic Review 80, 689-713. 
Fama, E. F., and A. Farber (1979): Money, Bonds, and Foreign Exchange, American Economic Review, 69(4), 639-649.

Frenkel, J. A. (1978): Purchasing Power Parity: Doctrinal Perspective and Evidence from the 1920s, Journal of International Economics, 8, 169-191.

Frenkel, J. A. (1981): The Collapse of Purchasing Power Parities during the 1970s, European Economic Review, 16, 145-165.

Grauer, F. I. A., R. H. Litzenberger, and R. E. Stehle (1976): Sharing Rules and Equilibrium in an International Market under Uncertainty, Journal of Financial Economics 3(3), 233-256.

Hakkio, C. S. (1984): A Re-examination of Purchasing Power Parity: a Multi-Country and Multi-Period Study, Journal of International Economics, 8, 265-277.

Hamilton, J., (1990): Analysis of Time Series Subject to Changes in Regime, Journal of Econometrics 45, 39-98.

Hansen, L. P. and R. J. Hodrick (1980): Forward Exchange Rates as Optimal Predictors of Future Spot Rates: An Econometric Analysis', Journal of Political Economy, 88, 829852.

Huang, R. D. (1990): Risk and Parity in Purchasing Power, Journal of Money, Credit and Banking, 22.3, 338-356.

Huizinga, J. (1987): An Empirical Investigation of the Long Run Behavior of Real Exchange Rates, Carnegie-Rochester Series on Public Policy, 149-214.

Hull, J. (1989): Options, Futures, and Other-Derivative Securities, Prentice Hall.

Isard, P. (1977): How Far Can We Push the Law of One Price, American Economic Review, 942-948.

Kaminsky, G. (1993): Is There a Peso Problem: Evidence from the Dollar/Pound Exchange Rate, 1976-87, American Economic Review 83, 450-472.

Kim, Y. (1990): Purchasing Power in the Long Run: A Cointegration Approach, Journal of Money, Credit and Banking, 22, 491-503.

Koedijk, K. and P. Schotman (1990): How to beat the Random Walk. An Empirical Model of Real Exchange Rates, Journal of International Economics, 29, 311-332.

Kravis, I. B. and R. E. Lipsey (1977): Export Prices and the Transmission of Inflation, American Economic Review, 155-163.

Kravis, I. B., Z. Kennessey, A. W. Heston and R. Summers (1975): A System of International Comparisons of Gross Products and Purchasing Power, John Hopkins Press, Baltimore.

Krugman, P. (1987): Pricing to Market When the Exchange Rate Changes, in S. Arndt and J. Richardson (eds.), Real Financial Linkages Among Open Economies, M.I.T. Press, Cambridge, Mass.

Margrabe, W. (1978): The Value of an Option to Exchange One Asset for Another, Journal of Finance 33(1), 177-186. 
Marston, R. (1990), Pricing to Market in Japanese and U.S. Manufacturing, Journal of International Economics 29, 217-236.

McNown, R. and M. S. Wallace (1989): National Price Levels, Purchasing Power Parity, and Cointegration: a Test of Four High Inflation Economics, Journal of International Money and Finance, 8, 533-546.

Merton, R. C. (1973): The Theory of Rational Option Pricing, Bell Journal of Economics and Management Science, 4(1), 141-183.

Phylaktis, K. and Y. Kassimatis (1992): Does the Real Exchange Rate follow a Random Walk? The Pacific Basin Perspective, Research Report, City University Business School, London.

Richardson, J. D. (1978): Some Empirical Evidence on Commodity Arbitrage and the Law of One Price, Journal of International Economics, 341-351.

Rogalski, R., and J. D. Vinso (1977): Price Level Variations as Predictors of Flexible Exchange Rates, Journal of International Business Studies, 1977, 71-81.

Roll, R. (1979): Violations of Purchasing Power Parity and Their Implications for International Commodity Markets, in Sarnat, M. and Szego, G.P. (eds.): International Finance and Trade, 1, Cambridge, 133-179.

Rush, M. and S. Husted (1985): Purchasing Power Parity in the Long Run, Canadian Journal of Economics, 18, 137-145.

Samuelson, P., and S. Swamy (1974): Invariant Index Numbers and Canonical Duality: Survay and Synthesis, American Economic Review, 64(3), 566-593.

Sercu, P. (1980): A Generalization of the International Asset Pricing Model, Journal de l'Association Francaise de Finance 1(1), 40-73.

Solnik, B. (1974): The International Pricing of Risk: An Empirical Investigation of the World Capital Market Structure, Journal of Finance 29(2), 365-378.

Stulz, R. (1981): A Model of International Asset Pricing, Journal of Financial Economics, 9(4), 386-404.

Taylor, M. P. (1988): An Empirical Examination of Long-Run Purchasing Power Parity using Cointegration Techniques, Applied Economics, 20, 1369-1381.

Uppal, R. (1993), A General Equilibrium Model of International Portfolio Choice, Journal of Finance, 48(2), 529-553. 
Figure 1

When the countries are fully symmetric (except for their random output of the tradeable good), the critical loci that separate the no-trade domain from the domain with trade are symmetric rays, $Q=q K$ and $Q=q / K$. For $Q: q>K(<\kappa)$ there will be imports (exports), and elsewhere there is no trade.

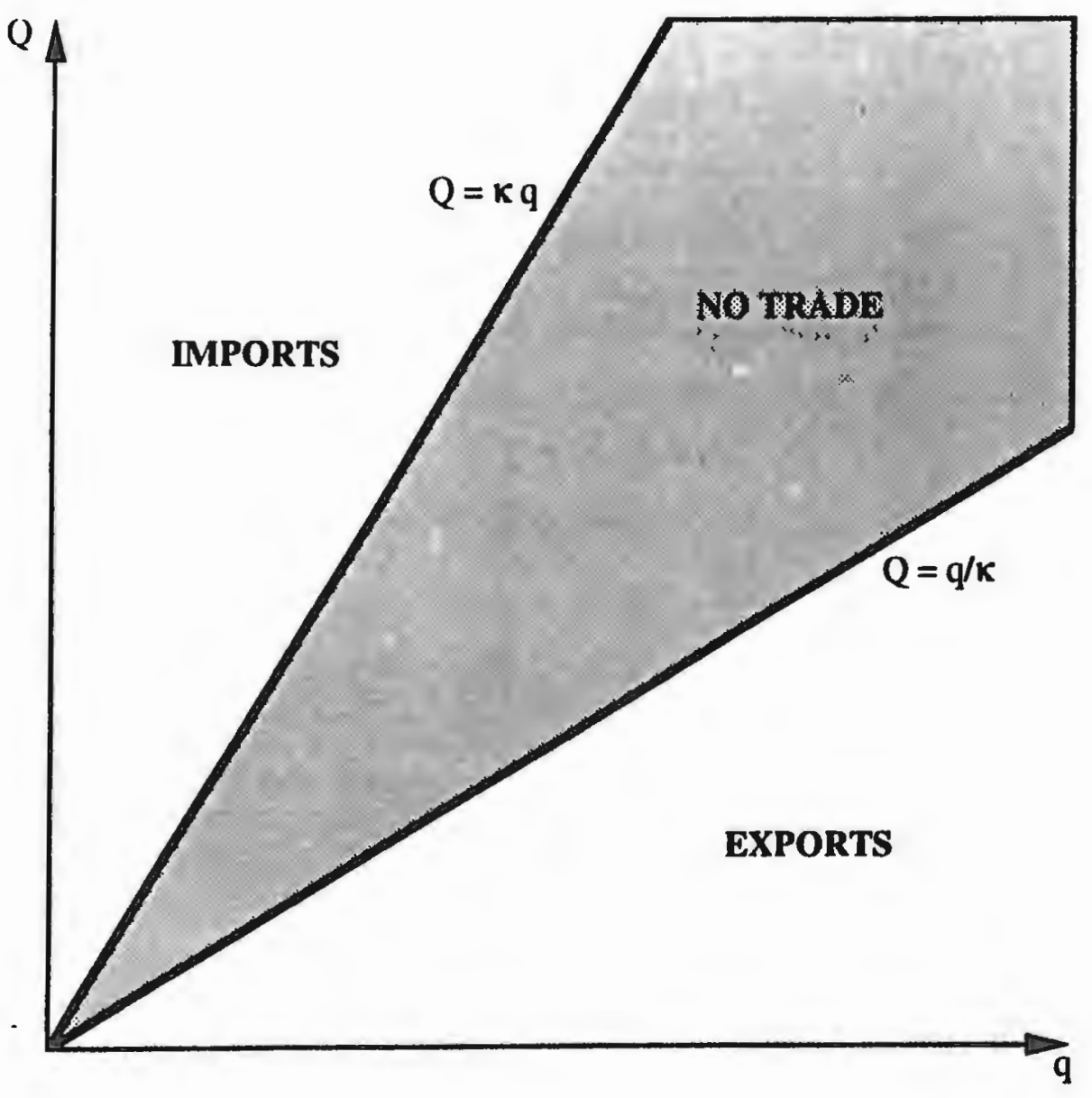




\section{Figure 2a}

In this figure, we show the exchange rate and the bounds on it as a function of the relative outputs of the traded good at home and abroad, when the value of $\beta$ is positive and $m(t) / M(t)=1$. The graph is divided into the no-trade region, $1 / \kappa<Q / q<\kappa$, and the regions outside these bounds. Note that, in the no-trade region, the commodity price parity line is the 45-degree line. This is because $p(t) / P(t)=C(t) / c(t)$, which equals $Q(t) / q(t)$ when there is no trade. In contrast, outside the no-trade region, $C(t) / \mathrm{c}(t)$ is a constant, implying a flat price-parity line. The upper and lower bounds on the exchange rate immediately follow from the ratio $p(t) / P(t)$. In the region where $Q(t) / q(t)<1 / \kappa[>\mathrm{k}]$, the exchange rate is at the upper [lower] bound. In the no-trade region, however, the exchange rate lies within the price band, and approaches the lower bound as $Q(t) / q(t)$ approaches $\kappa$. Note that within the no-trade region the slope of the exchange rate is less steep than that of the price parity line, $p(t) / P(t)$. In this figure, $\varepsilon=0.25, \tau=0.25$, and $\eta=5$.

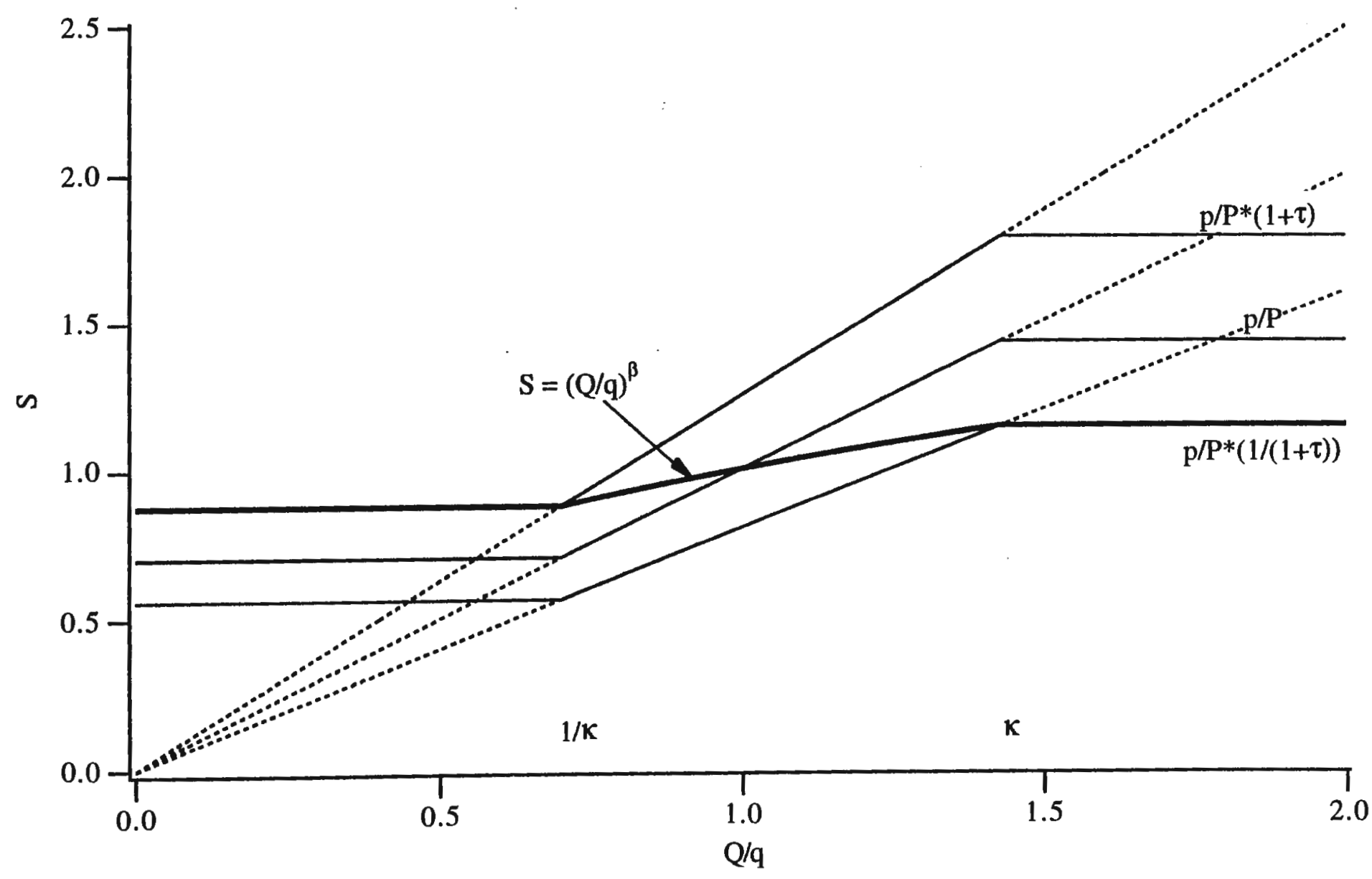




\section{Figure 2b}

In this figure, we show the exchange rate and the bounds on it as a function of the relative outputs of the traded good at home and abroad, when the degree of relative risk aversion is larger $(\eta=5.0$ ), implying a negative value for $\beta$. Compared to Figure 2a, the no-trade region contracts. The effect of this on the exchange rate is that within the no-trade region the exchange rate actually decreases as a function of $Q(t) / q(t)$.

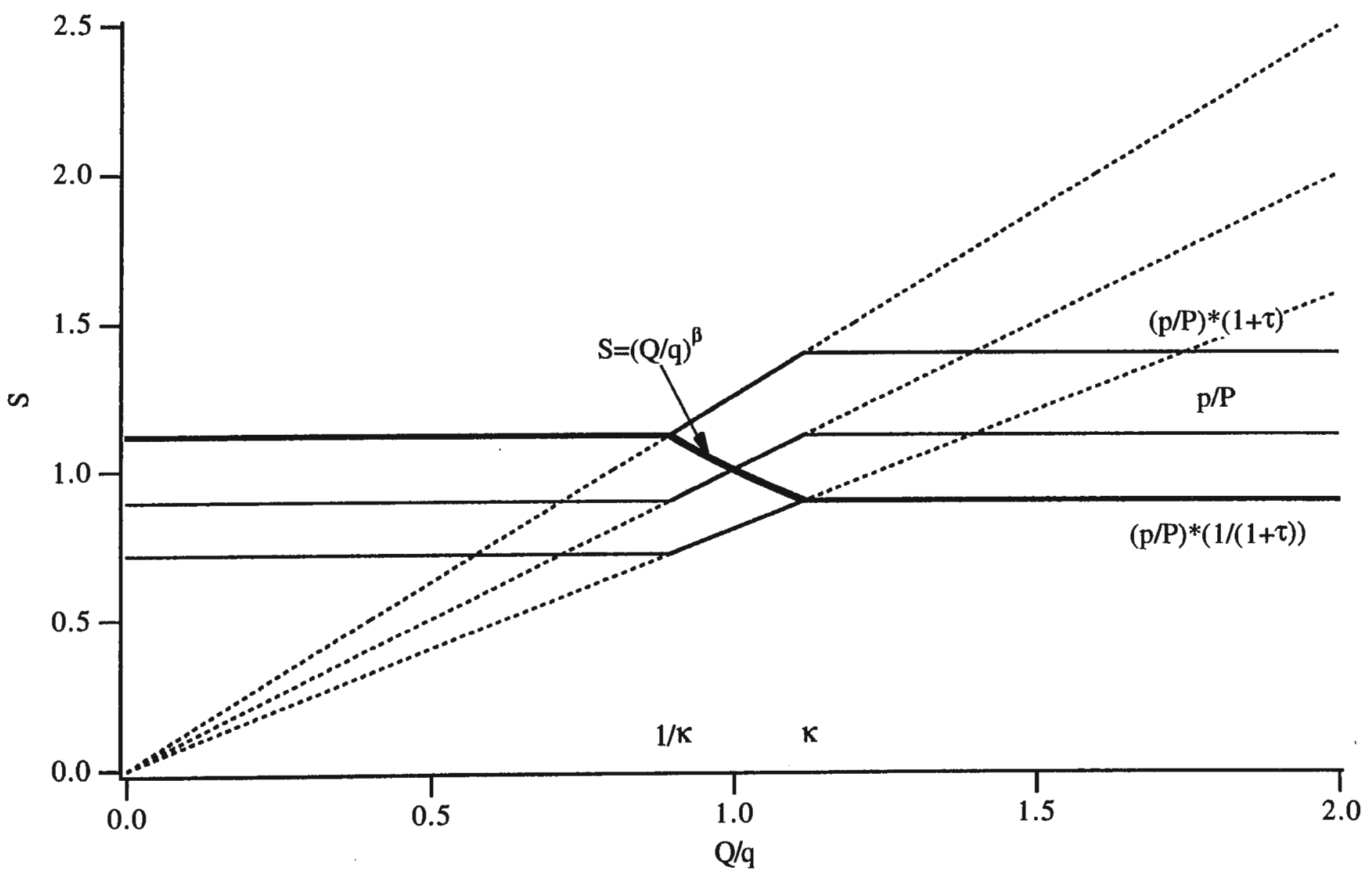




\section{Figure 3a}

Figure 3a shows $\ln S(t)$ as a function of $\ln [p(t) / P(t)]$, for $m(t) / M(t)=1$. The band for $\ln S(t)$ now is the 45 -degree line plus or minus $\ln (1+\tau)$. For low [high] values of $\ln [p(t) P(t)], \ln S(t)$ is at the upper [lower] bound, while it gradually moves from the upper to the lower bound when $-\ln \kappa<\ln S(t)<$ In $\kappa$. With risk-aversion below unity and, therefore, a positive $\beta$, this no-trade region is relatively wide, and $\ln S(t)$ is a positive function of $\ln [p(t) / P(t)]$ within this domain but with a slope less than unity.

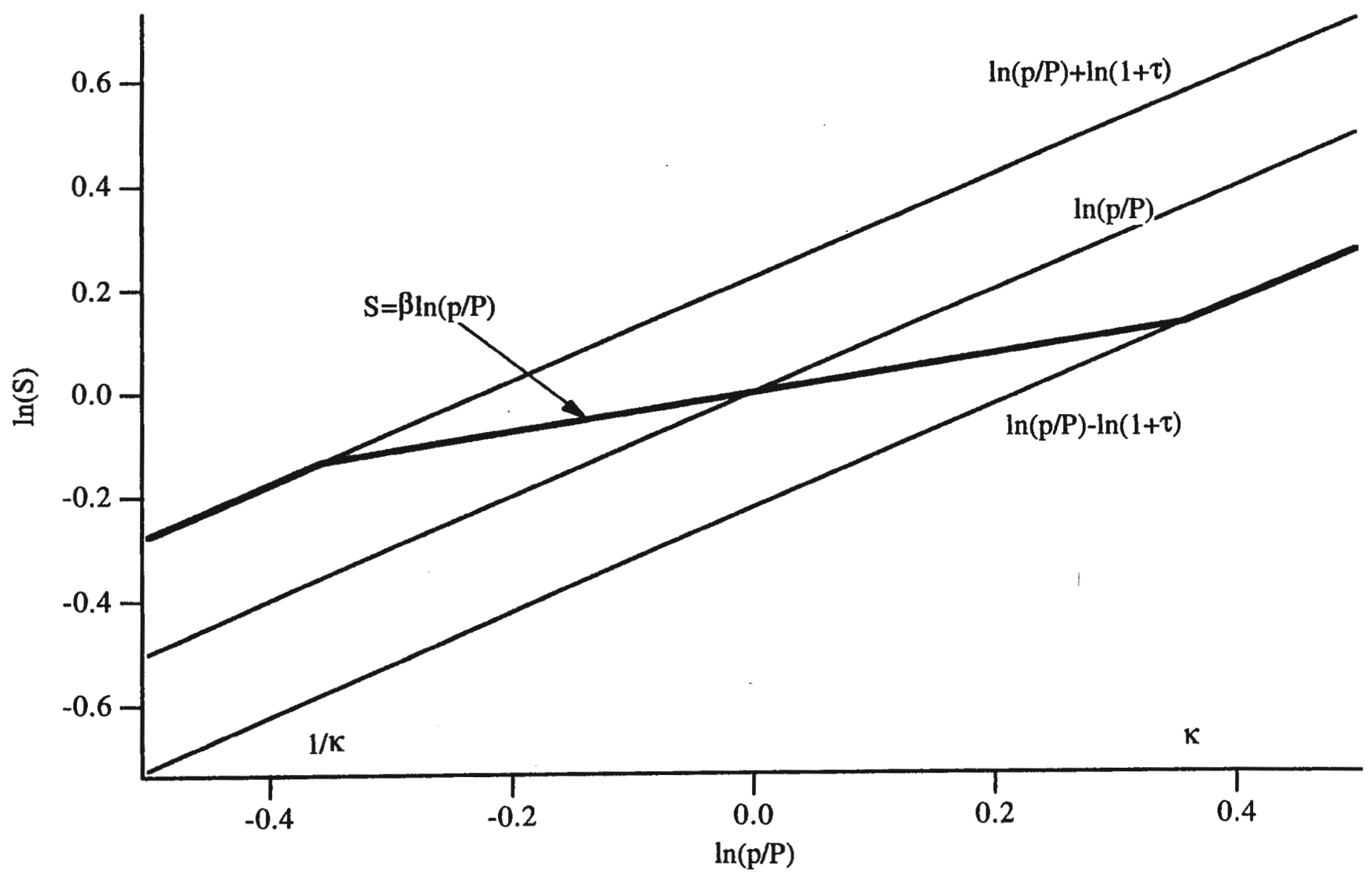


Figure 3b

In Figure $3 \mathrm{~b}$, risk aversion is above unity, implying that $\beta$ is negative. This means that the no-trade domain contracts as compared to the previous case, and that within this domain the log exchange rate drops as $\ln [p(t) / P(t)]$ increases.

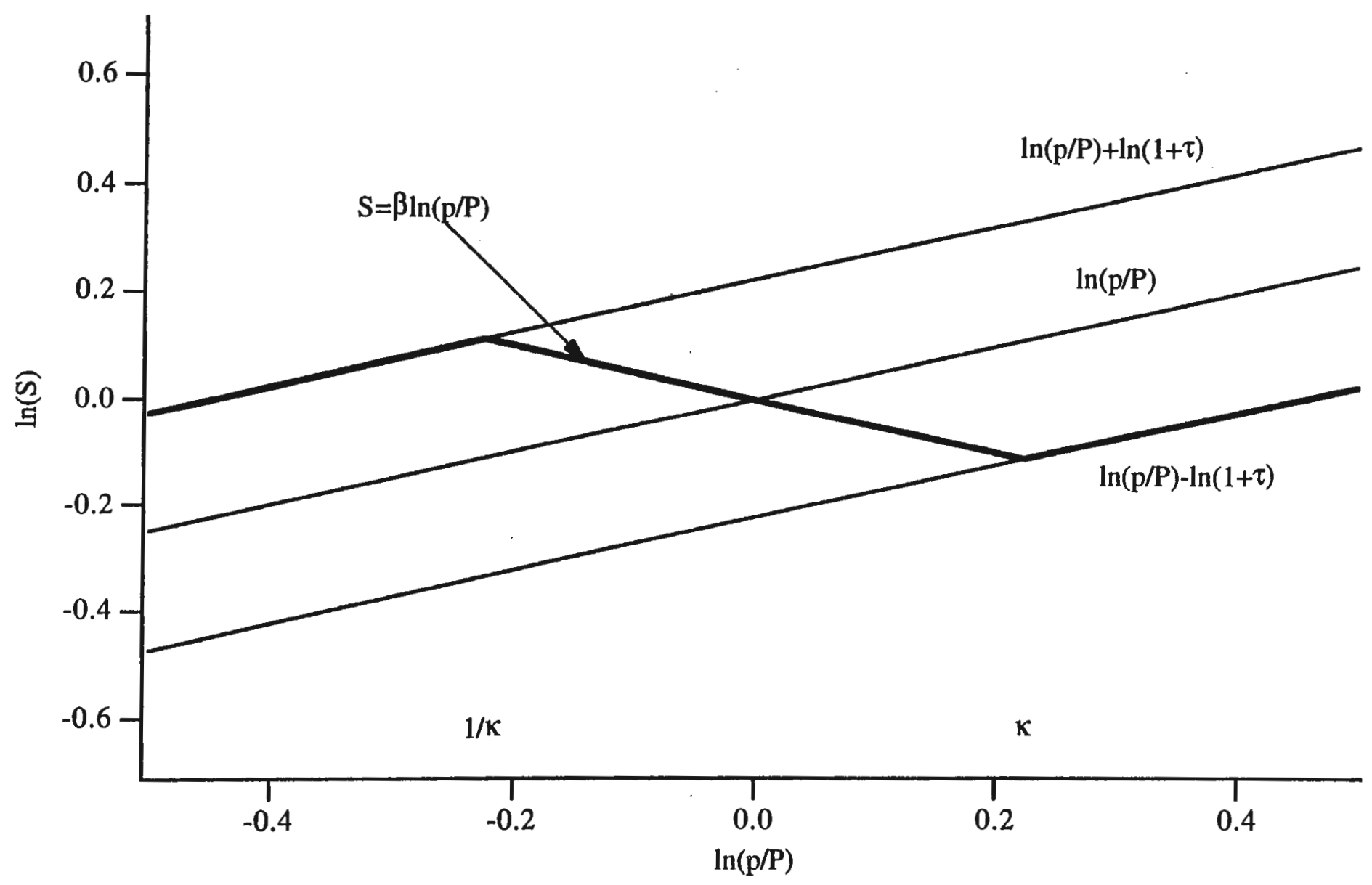

